\title{
Deficiency of $\alpha 7$ Nicotinic Acetylcholine Receptor Attenuates Bleomycin-Induced Lung Fibrosis in Mice
}

\author{
Peiyu Sun, ${ }^{1^{*}}$ Ling $\mathrm{Li}^{2^{*}}$ Caiqi Zhao, ${ }^{2}$ Mengyao Pan, ${ }^{2}$ Zhikang Qian, ${ }^{3}$ and Xiao Su ${ }^{2}$
}

${ }^{1}$ Life and Environment Science College, Shanghai Normal University, Shanghai, China; ${ }^{2}$ Unit of Respiratory Infection and Immunity, Key Laboratory of Molecular Virology and Immunology, Institut Pasteur of Shanghai, Chinese Academy of Sciences, Shanghai, China; and ${ }^{3}$ Unit of Herpesvirus and Molecular Virology, Institut Pasteur of Shanghai

\begin{abstract}
$\alpha 7$ nicotinic acetylcholine receptor ( $\alpha 7 \mathrm{nAChR}$, coded by Chrna7) is indispensable in dampening proinflammatory responses. However, whether $\alpha 7 \mathrm{nAChR}$ plays a role in regulating bleomycin (BLM)-induced lung fibrosis is less investigated. Here, we challenged wild-type and Chrna $7^{--}$mice with BLM intratracheally to elicit lung fibrosis. Taking advantage of this model, we measured body weight loss, lung fibrogenic genes (Acta2, Collal, Fsp 1 and Fst17), histology, Masson's trichrome staining, hydroxyproline levels and expression of $\alpha$-SMA at protein levels in the BLM-challenged lung to evaluate the severity of lung fibrosis. We also pretreated human fibroblasts (MRC5 cell line) and isolated mouse lung fibroblasts with GTS-21 (an $\alpha 7$ nAChR agonist) to study its effects on TGF- $\beta$-stimulated profibrotic profiles. We found that lung Chrna7 expression and $\mathrm{CD}^{+} \mathrm{CHAT}^{+}$cells (choline acetyltransferase, an enzyme for local acetylcholine synthesis) were elevated 12-fold and 4.5-fold, respectively, in the early stage of lung fibrosis. Deletion of Chrna7 prevented body-weight loss and reduced lung fibrogenic genes (Acta2, Colla 1, Fsp 1 and Fstl7) and Arg 1 (coding arginase 1). Deletion of Chrna7 attenuated lung arginase $1^{+}$Ly $6 C^{+}$cells, Masson's trichrome staining, hydroxyproline levels and expression of $\alpha$-SMA at protein levels in BLM-challenged mice. Mechanistically, activation of $\alpha 7 \mathrm{nAChR}$ in human fibroblasts increased TGF- $\beta$-induced phosphorylation of Smad2/3 and transcription of fibrogenic genes (Acta2, Colla1). In isolated mouse lung fibroblasts, activation of $\alpha 7$ nAChR also enhanced TGF- $\beta$-induced transcription of fibrogenic genes; however, deletion of Chrna7 diminished these effects. Taken together, deficiency of $\alpha 7$ nAChR could suppress the development of BLMinduced lung fibrosis. Thus, $\alpha 7 \mathrm{nAChR}$ might be a novel therapeutic target for treating lung fibrosis.
\end{abstract}

Online address: http://www.molmed.org

doi: $10.2119 / \mathrm{molmed} .2016 .00083$

\section{INTRODUCTION}

Pulmonary fibrosis (PF) is an interstitial lung disease characterized by the destruction of pulmonary parenchyma together with deposition of extracellular matrix (ECM) in the interstitial and alveolar spaces (1-3). Mortality from PF remains high, since its cause remains elusive and its pathogenesis is incompletely understood (4).

During the development of lung fibrosis, epithelial lesions might result in aberrant wound healing activation (3), which promotes a multitude of mediators: transforming growth factor $\beta$ (TGF- $\beta$ ) (5), fibroblast-specific protein (FSP1) (6), follistatin-related protein 1 (FSTL1) (7); and signaling pathways: Sma and Mad homolog (Smad) (8), wingless-type MMTV integration site family member (Wnt- $\beta$-catenin) (9), phosphoinositide 3-kinase (PI3K-AKT) (10). Among these events, TGF- $\beta$ and its signaling play a key role in regulating fibrogenesis by

${ }^{*} P S$ and LL contributed equally to this work.

Address correspondence to Xiao Su, Unit of Respiratory Infection and Immunity, Institut Pasteur of Shanghai, Chinese Academy of Sciences, 320 Yueyang Road, Life Science Research BLD B104, Shanghai 200031, China. Phone/fax: 21-549231 1 1; E-mail: xsu@ips.ac.cn Submitted March 27, 2016; Accepted for Publication February 14, 2017; Published Online (www.molmed.org) March 6, 2017.

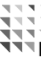

Feinstein Institute
for Medical Research Northwell Health

recruiting fibroblasts and inducing their differentiation to collagen-producing $\alpha$ smooth muscle actin ( $\alpha$-SMA)-expressing myofibroblasts $(11,12)$.

Mechanistically, TGF- $\beta$ can activate its receptor and promotes serine phosphorylation and formation of SMAD2/ SMAD3:SMAD4 heterodimer (13), which translocates to the nucleus to initiate transcription of profibrotic genes (Acta2, Col1a1, Fsp1 and Fstl1) (14). Many factors (such as AKT1, protein-tyrosine phosphatase 1B [PTP1B] and PTP1A) can modify TGF- $\beta$ signaling (including its receptors and Smads), which affects fibrogenesis (14-17). Whether nicotinic acetylcholine receptor $(\alpha 7 \mathrm{nAChR})$ is a regulatory factor of TGF- $\beta$ signaling is not quite clear.

As we know, $\alpha 7 \mathrm{nAChR}$ can be activated by acetylcholine, a neurotransmitter of the vagus nerve, and plays an indispensable role in the 
cholinergic antiinflammatory pathway (18). It has been reported that the vagus nerve innervates the distal airway of the lung, especially in the alveoli $(19,20)$. Activation of $\alpha 7 \mathrm{nAChR}$ could attenuate acid aspiration, endotoxin or Escherichia coli-induced acute lung inflammation and injury $(21,22)$. Vagus nerve through $\alpha 7 \mathrm{nAChR}$ could modulate lung infection, inflammation and immunity (23). The regulatory effect of $\alpha 7 \mathrm{nAChR}$ on proinflammatory cells in the above-mentioned models has been well documented. Whether activation of $\alpha 7 \mathrm{nAChR}$ can affect TGF- $\beta$ signaling and transcription of profibrotic genes in fibroblasts, therefore regulating the development of lung fibrosis, is less investigated.

Studies have demonstrated that acetylcholine (ACh), a neurotransmitter of the vagus nerve, can promote proliferation of fibroblasts (24-26). Nicotine may directly interact with $\alpha 7 \mathrm{nAChR}$ to increase collagen accumulation in the airway and alveolar walls following nicotine exposure in utero (27). Unilateral vagotomy was shown to attenuate deposition of collagen by decreasing numbers of fibrogenic cells and cytokines (TGF- $\beta$ and IL-4) in a BLM-induced lung fibrosis mouse model (16).

Therefore, in this study, we hypothesized that activation of $\alpha 7 \mathrm{nAChR}$ would enhance TGF- $\beta$ signaling, which facilitates BLM-induced fibrosis; conversely, deficiency of $\alpha 7 \mathrm{nAChR}$ would lessen BLM-induced lung fibrosis. We took advantage of fibroblast culture and BLM-induced lung fibrosis mouse models to investigate (1) whether deletion of Chrna 7 would reduce expression of fibrogenic genes in the early stage of the BLM-induced lung fibrosis mouse model, (2) whether deletion of Chrna 7 would attenuate collagen deposition (Masson's trichrome staining) in BLMinduced lung fibrosis, and (3) whether activation of $\alpha 7 \mathrm{nAChR}$ would regulate TGF- $\beta$ signaling and transcription of fibrogenic genes. The results of this study will provide novel therapeutic targets for combating lung fibrosis.

\section{MATERIALS AND METHODS}

\section{Animals}

$\alpha 7$ nAChR knockout mice (Chrna7'-/-, B6.129S7-Chrna7 ${ }^{\text {tm1Bay }} / J$, background C57BL/6J, stock no. 003232) were purchased from Jackson Laboratory (Bar Harbor, ME, USA) (21,22). Littermate wild-type mice were used as controls. The mice were housed in groups with $12 \mathrm{~h}$ dark/light cycles and with free access to food and water. Eight- to $10-w k-$ old male wild-type and Chrna $7^{-/-}$mice were used for the experiments. Anesthesia was induced with intraperitoneal (ip) injection of pentobarbital sodium, $50 \mathrm{mg} / \mathrm{kg}$. All animal studies were approved by the Committees on Animal Research of the Institut Pasteur of Shanghai, Chinese Academy of Sciences, China.

\section{Antibodies and Reagents}

AChRa7 (H-302) (sc-5544), COL1A1 (D-13) (sc-25974), Smad2/3 (FL-425) (sc-8332), $\alpha$-actin (1A4) (sc-32251) and arginase I (sc-20150) antibodies were from Santa Cruz Biotechnology (Santa Cruz, CA, USA). Anti-nicotinic acetylcholine receptor $\alpha 7$ (ab24644), anti-PTP1B (phospho S378) [EP1840Y] (ab76239), anti-collagen I (ab34710) and anticholine acetyltransferase [EPR13024(B)] (ab181023) antibodies were from ABCAM (Cambridge, MA, USA). Phospho-Smad2 (Ser465/467)/Smad3 (Ser423/425) (D27F4) rabbit mAb (8828S) was from Cell Signaling (Danvers, MA, USA). Fluorescein isothiocyanate (FITC) or PE-CD4, Ly6C and Ly6G antibodies were from eBioscience (San Diego, CA, USA). Bleomycin sulfate (S1214) was from Selleck Chemicals (Houston, TX, USA). GTS-21 dihydrochloride (DMBX-A) (ab120560) was from ABCAM. Human and mouse TGF- $\beta 1$ recombinant protein (14-8348-62 and 14-8342-62) was from eBioscience. Human/mouse TGF- $\beta 1$ enzyme-linked immunosorbent assay (ELISA) kit (88-8350-88) was from eBioscience.

\section{Cell Lines and Culture}

Human embryonic lung fibroblasts (MRC5, a gift from Professor Zhikang
Qian, Institut Pasteur Shanghai of Chinese Academy of Sciences) and A549 cells (type II lung epithelial cells; ATCC, Manassas, VA, USA) were maintained in Dulbecco's modified Eagle medium supplemented with $10 \%$ fetal bovine serum (FBS). In all, $2 \times 10^{5}$ cells were seeded per well and cultured overnight or until $90 \%$ confluency in 12-well plate. The cells were pretreated with GTS-21 $30 \mathrm{~min}$ prior to rhTGF- $\beta 1(5 \mathrm{ng} / \mathrm{mL})$ stimulation. The cells were collected at $24 \mathrm{~h}$ after stimulation for qPCR or immunoblotting analysis.

\section{Packing of shRNA Ptpn 1 and Lentiviral Transfection}

The small-interfering RNA oligonucleotide was synthesized by Shanghai ShengGong Biotechnology for gene silencing of Ptpn1: human NM_002827.3, scramble CAACAAGATGAAGAGCACCAA and shRNA Ptpn1 CTGTGATCGAAGGTGCCAAAT. The shRNA sequences were inserted into pLKO.1 plasmid between the EcoRI and NheI sites. The scrambled or Ptpn1-shRNA pLKO.1 was cotransfected with vesicular stomatitis virus (pseudotyping lentiviral vector) in HEK-293T cells. Viruses were harvested by centrifugation and filtration $48 \mathrm{~h}$ post-transfection.

\section{BLM-Induced Lung Fibrosis}

The BLM-induced lung fibrosis mouse model was established as previously described (28). The BLM was delivered to the airspaces of the lung by the direct visualized instillation method (29). We chose a high dose of BLM at $3 \mathrm{mg} / \mathrm{kg}$ and followed for $7 \mathrm{~d}$, a middle dose at $1.5 \mathrm{mg} / \mathrm{kg}$ for $14 \mathrm{~d}$ and a low dose at $0.5 \mathrm{mg} / \mathrm{kg}$ for $21 \mathrm{~d}$ to induce lung fibrosis. These three conditions separately represent early, developing and advanced stages of BLM-induced lung fibrosis.

\section{Lung Histology, Masson's Trichrome Staining and Histomorphometrical Analysis}

Hematoxylin and eosin (H\&E) and Masson's trichrome staining of lungs 
were conducted as described previously $(28,30,31)$. The severity of fibrosis in H\&E-stained lungs was quantified by the Ashcroft scoring system (15,32): 0, normal lung; 1 , isolated alveolar septa with gentle fibrotic changes; 2 , fibrotic changes of alveolar septa with knot-like formation; 3, contiguous fibrotic walls of alveolar septa; 4 , single fibrotic masses; 5 , confluent fibrotic masses; 6 , large contiguous fibrotic masses; 7 , air bubbles; 8 , fibrous obliteration. The grades of pulmonary fibrosis were analyzed by a professional researcher of pathology, who was blinded to groups.

For histomorphometrical analysis (33), three randomly chosen regions per lung sample were registered by a digitizing camera applied to a light microscope with a $10 \times$ objective, each field corresponding to a test area of $1.3 \mathrm{~cm}^{2}$. Each object, such as aerated lung area (H\&E staining, an indication of severity of lung consolidation), blue-stained area (trichrome staining, an index of mature collagen deposition), and sum or mean optical density of blue-stained area (an indication of quantity of collagen deposition), was separately quantified by Image Pro-Plus version 6.0 (Media Cybernetics, Rockville, MD, USA). Segmentation of objects, spatial calibration, threshold selection, background subtraction and other steps were preceded in each analysis. Values from three randomly chosen regions for each mouse lung were averaged.

\section{Isolation of Mouse Lung Primary Fibroblasts}

The chests of the mice were opened and the lung vascular beds were flushed by injecting $5 \mathrm{~mL}$ of chilled $\left(4^{\circ} \mathrm{C}\right) \mathrm{PBS}$ into the right ventricle. Lungs were excised, minced and digested in DMEM/F-12K (Gibco) collagenase (Sigma) solution at $37^{\circ} \mathrm{C}$ for $1 \mathrm{~h}$. Dissociated cells were transferred to a $15 \mathrm{~mL}$ conical tube and centrifuged for $10 \mathrm{~min}$ $\left(335 \times \mathrm{g}, 4^{\circ} \mathrm{C}\right)$. The red cells were lysed by adding $2 \mathrm{~mL}$ of ACK lysing buffer for $5 \mathrm{~min}$ at room temperature. The cells were washed with $13 \mathrm{~mL}$ of cold
PBS/0.5\% bovine serum albumin (BSA) for $10 \mathrm{~min}\left(335 \times \mathrm{g}, 4^{\circ} \mathrm{C}\right)$. The cell pellets were resuspended in $5 \mathrm{~mL}$ of cold PBS $/ 0.5 \%$ BSA and filtered with a 70 $\mu \mathrm{m}$ nylon mesh. The cells were plated in tissue culture dishes with DMEM/F$12 \mathrm{~K}$ media with antibiotics / antimycotic (Gibco) and cultured at $37^{\circ}, 5 \% \mathrm{CO}_{2}$. After confluent, the cells were replated in DMEM media supplemented with 15\% FBS, nonessential acids, 100 units / $\mathrm{mL}$ penicillin and $100 \mu \mathrm{g} / \mathrm{mL}$ streptomycin.

\section{Immunofluorescence of Collagen 1 Staining in Lung Primary Fibroblasts and Confocal Microscopy}

The cells were cultured on coverslips in 12 -well plates. The cells were fixed by $2 \%$ paraformaldehyde and permeabilized by $0.1 \%$ Triton X-100. To reduce nonspecific binding, the cells were treated with blocking buffer (5\% BSA in PBS) for $2 \mathrm{~h}$.

The cells were incubated with rabbit anticollagen 1 (300 $\mu \mathrm{L}, 1: 400$, each coverslip) antibody or control antibody. After complete washing, the cells were incubated with goat-anti-rabbit FITClabeled secondary antibody $(300 \mu \mathrm{L}$, 1:500) for $60 \mathrm{~min}$. To visualize nucleus, the cells were counterstained with DAPI. The coverslips were sealed and desiccated for $30 \mathrm{~min}$ before image analysis. Confocal microscopy was carried out using an Olympus FV-1200 laser scanning microscope. Images in $1024 \times 1024$ format were acquired in the DAPI and Alexa Fluor 488 channels, and processed using the attached software.

\section{Flow Cytometry Analysis}

To determine $\alpha 7 \mathrm{nAChR}$ expression, the human fibroblasts (MRC5) and mouse lung primary fibroblasts were harvested and stained with Fluor-633 $\alpha$-BTX (Biotium, Hayward, CA, USA) at $0,0.25,0.5,1$ and $2 \mu \mathrm{g} / \mathrm{mL}$. In the digested lung cells, fluorescent Ly6C, CD4, arginase 1 and CHAT antibodies were used to detect $\mathrm{CD}^{+} \mathrm{CHAT}^{+}$and arginase $1^{+} \mathrm{Ly} 6 \mathrm{C}^{+}$cells. The bronchoalveolar lavage [BAL] cells were labeled with anti-Ly6C and anti-Ly6G antibodies to detect monocytes and neutrophils.
Fluorescent cells were analyzed after exclusion of debris and aggregates with LSRFortessa (BD Biosciences, San Jose, CA USA). Data were analyzed by Flowjo 7.6 (Tree Star Inc., Ashland, OR, USA).

\section{Western Blotting Analysis}

As previously described $(21,22)$, denatured proteins were equally loaded and run on a $10 \%$ gradient Bis-Tris gel (Invitrogen, Carlsbad, CA, USA). The proteins were resolved by electrophoresis, transferred to a polyvinylidine difluoride membrane, hybridized with indicated primary antibodies and corresponding horseradish peroxidase-labeled secondary antibodies, and visualized using a Western ECL Substrate Kit. The optical density in the blotting band was analyzed by Image J software (National Institutes of Health, Bethesda, MD USA; https:/ /imagej.nih.gov/ij/).

\section{Quantitative Real-time Polymerase Chain Reaction}

Total RNA was extracted from homogenized lungs or whole cells using TRIzol reagent (Invitrogen) following the manufacturer's instructions. cDNA was synthesized using a reverse transcriptase kit (TaKaRa, Beijing, China), followed by quantitative real-time polymerase chain reaction (RT-PCR) analysis (SYBR Green, TaKaRa). The sequences of the used primers were as follows:

Murine primers for animal experiments: Acta2 (NM_007392.2) 5'-GTCCCAGACATCAGGGAGTAA-3' (forward) and 5'-TCGGATACTTCAGCGTCAGGA-3' (reverse) (34);

Col1a1 (NM_007742.3), 5-GCAACAGTCGCTTCACCTACA-3' (forward) and 5-CAATGTCCAAGGGAGCCACAT-3' (reverse) (35);

Fsp1, (NM_011311.2) 5'-AGGAGCTACTGACCAGGGAGCT-3' (forward) and 5'-TCATTGTCCCTGTTGCTGTCC-3' (reverse) (36);

Fstl1 (NM_008047.5), 5'-TTATGATGGGCACTGCAAAGAA-3' (forward) and 5'-ACTGCCTTTAGAGAACCAGCC-3'(reverse) (7); 
Cxcl2 (NM_009140.2), 5'-CGCTGTCAATGCCTGAAG-3' (forward) and 5'- GGCGTCACACTCAAGCTCT-3' (reverse) (37); Mcp1 (NM_011333.3), 5'-GAAGGAATGGGTCCAGACAT-3' (forward) and 5'- ACGGGTCAACTTCACATTCA-3' (reverse) (38);

Arg1 (NM_007482.3), 5'-AGACCACAGTCTGGCAGTTG-3' (forward) and 5'- CCACCCAAATGACA-

CATAGG-3'(reverse) (39).

Il6 (NM_031168.1), 5'-GGCCTTCCCTACTTCACAAG-3' (forward) and 5'- ATTTCCACGATTTCCCAGAG-3' (reverse)(40).

Homo sapiens primers for cell culture:

Ptpn1 (NM_002827.2), 5'-ACACATGCGGTCACTTTTGG-3' (forward) and 5'-CGAGTTTCTTGGGTTGTAAGGT-3' (reverse);

Col1a1 (NM_000088.3), 5'-ATCAACCGGAGGAATTTCCGT-3' (forward) and 5'- CACCAGGACGACCAGGTTTTC -3' (reverse);

Acta2 (NM_001141945.1), 5'-AAAAGACAGCTACGTGGGTGA-3' (forward) and 5'-GCCATGTTCTATCGGGTACTTC-3' (reverse) (41);

Fsp1 (NM_002961.2), 5'-GATGAGCAACTTGGACAGCAA-3' (forward) and 5'-CTGGGCTGCTTATCTGG-

GAAG-3' (reverse) (42);

Ftsl1 (NM_007085.4), 5'-GAGCAATGCAAACCTCACAAG-3' (forward) and 5'-CAGTGTCCATCGTAAT-

CAACCTG-3' (reverse).

The relative expression levels of corresponding genes were determined by the $2^{-\triangle \Delta C T}$ method (43), normalized by GAPDH.

\section{Measurement of Lung Hydroxyproline}

The hydroxyproline in the supernatant of lung homogenate was measured by a hydroxyproline assay kit (Nanjing Jiancheng Bioengineering Institute, Nanjing, China). The experimental procedures were according to the manufacturer's instructions.

\section{Statistical Analysis}

Statistics were done with GraphPad Prism software (GraphPad, San Diego,
CA, USA). Student $t$ test was used unless there were multiple comparisons, in which case we used one-way analysis of variance (ANOVA) with Bonferroni post hoc test or 2-way ANOVA (significance level set at $P<0.05)$. The results are shown as mean \pm standard deviation.

\section{RESULTS}

\section{Deficiency of $\alpha 7$ nAChR Prevents Body-weight Loss and Reduces BAL Leukocytes and Blood Monocytes in the Early Stage of BLM-Induced Lung Fibrosis}

Development of lung fibrosis is accompanied by infiltration of proinflammatory cells, such as monocytes or macrophages (44). To test whether deficiency of $\alpha 7 \mathrm{nAChR}$ affects inflammatory cells in the early stage of BLM-induced lung fibrosis, we challenged Chrna7 ${ }^{+/+}$and Chrna7 $7^{-/}$mice with a high dose of BLM (3 mg/ $\mathrm{kg})$ intratracheally. At $7 \mathrm{~d}$, less body-weight loss (an indicator of sickness) was found in BLM-challenged Chrna ${ }^{-/}$mice compared to BLM-challenged Chrna ${ }^{+/+}$ mice (Figure 1A, initial body weights: wild-type, $26.6 \pm 1.5 \mathrm{~g}$; Chrna $^{-/}$, $27.6 \pm$ $1.6 \mathrm{~g})$. There was no difference in BAL leukocytes and protein levels (indicators of lung epithelial and vascular permeability) (21) between BLM-challenged Chrna7 $^{+/+}$and Chrna7 ${ }^{-/}$mice in these two groups (Figures 1B, C). Blood monocytes and eosinophils were decreased in BLM-challenged Chrna7 ${ }^{-/}$mice compared to BLM-challenged Chrna $7^{+/+}$ mice (Figures 1D, E), but there was no difference in blood neutrophils, lymphocytes or hematocrit (an index of systemic vascular leakage) (45) between these two groups (Figures $1 \mathrm{~F}-\mathrm{H}$ ).

\section{Lung $\mathrm{CD}^{+} \mathrm{CHAT}^{+}$Cells Were Increased in the Early Stage of BLM- Induced Lung Fibrosis}

Since CHAT-expressed lymphocyte-derived ACh could regulate local innate immune response (46), we analyzed $\mathrm{CD}^{+} \mathrm{CHAT}^{+}$cells in the digested lung in the early stage of BLM-induced lung fibrosis by flow cytometry.

We found that $\mathrm{CD}^{+} \mathrm{CHAT}^{+}$cells in the lung increased 4.5-fold in BLM-challenged wild-type and Chrna $7^{-/}$mice at 7 d. Lung $\mathrm{CD}^{+} \mathrm{CHAT}^{+}$cells did not differ between BLM-challenged wild-type and Chrna7 ${ }^{-1-}$ mice (Figures 1I-J). This finding suggests that $\mathrm{CD} 4^{+} \mathrm{T}$ lymphocyte-derived ACh via $\alpha 7 \mathrm{nAChR}$ might contribute to the early development of BLM-induced lung fibrosis.

\section{Deficiency of $\alpha 7$ nAChR Reduces Lung Profibrotic Genes in the Early Stage of BLM-Induced Lung Fibrosis}

Using the same experimental setting

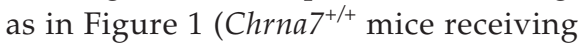
intratracheal saline were used as control), we sacrificed mice $7 \mathrm{~d}$ after intratracheal saline or BLM. We found that lung Chrna7 mRNA levels increased 12-fold in BLM-challenged Chrna ${ }^{+/+}$ mice compared to saline-challenged Chrna7 $^{+/+}$mice (Figure 2A), suggesting that $\alpha 7 \mathrm{nAChR}$ is involved in the early stage of BLM-induced lung fibrosis. The lung mRNA levels of fibrosis-related genes Acta2, Col1a1 and Fsp1 were increased in BLMchallenged Chrnat ${ }^{+/+}$mice compared to saline-challenged Chrna ${ }^{+/+}$mice; however, lung Acta2, Col1a1 and Fsp1 mRNA were downregulated in BLM-challenged Chrna $7^{--}$mice compared to BLM-challenged Chrna $7^{+/+}$mice (Figures 2B-D). These findings suggest that $\alpha 7 \mathrm{nAChR}$ is required for the transcription of profibrotic genes Acta2, Col1a1 and Fsp1 in the early stage of lung fibrogenesis.

We measured the inflammationrelated genes Cxcl2 (a chemokine for neutrophils), Mcp1 (a chemokine for monocytes) and Arg1 (an index of M2 macrophage activation) $7 \mathrm{~d}$ after BLM challenge. Lung Cxcl2 and Mcp1 were increased in BLM-challenged wild-type mice (Figures 2E-G) compared to saline-treated wild-type mice, but these genes were not different between BLM-challenged wild-type and Chrna7 knockout mice (Figures 2E, F). 

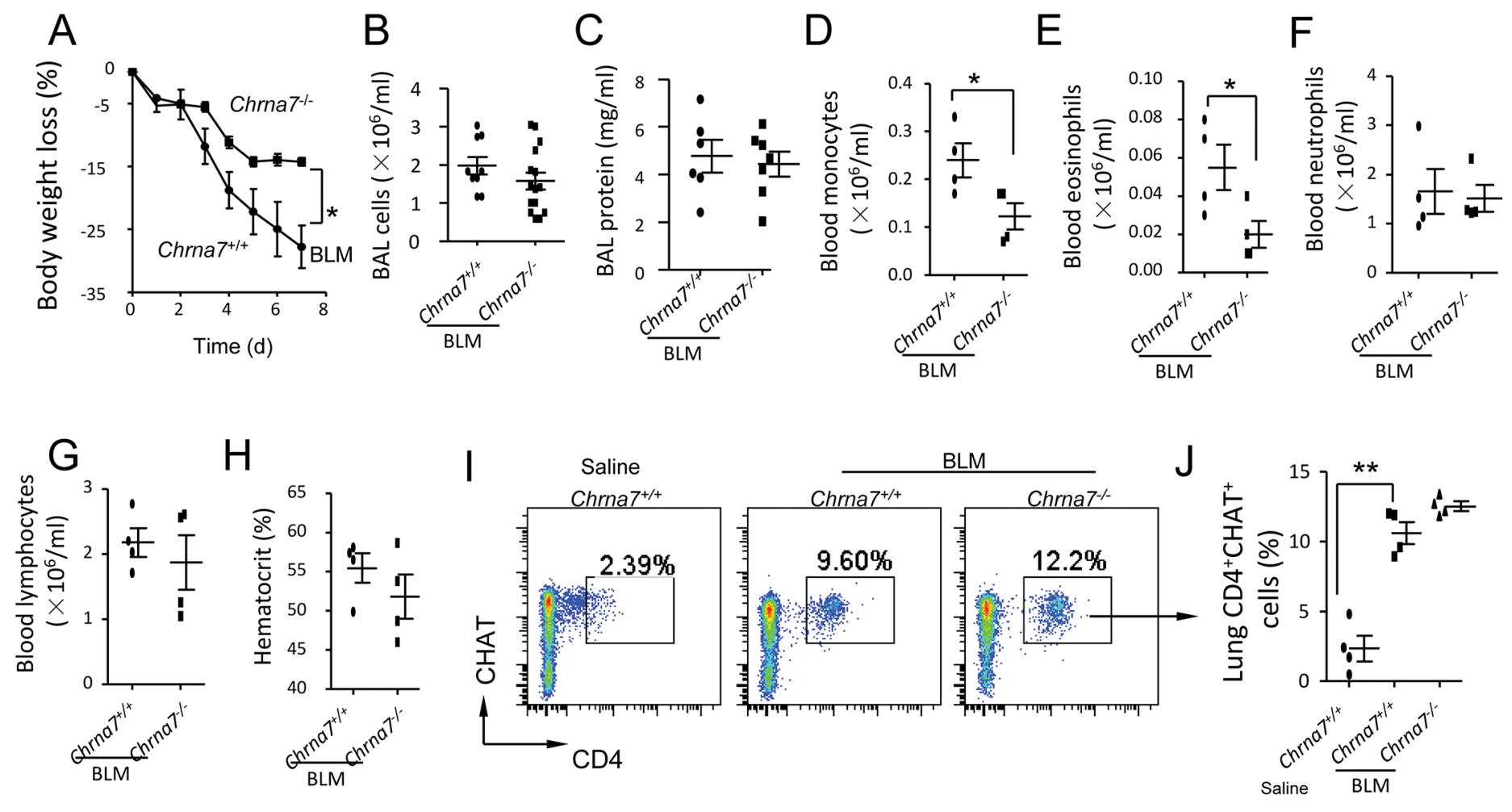

Figure 1. Deficiency of $\alpha 7$ nAChR affects body-weight loss, BAL and blood profiles, and lung $\mathrm{CD}^{+} \mathrm{CHAT}^{+}$cells in the early stage of BLM-induced lung fibrosis. (A) Effect of $\alpha 7$ nAChR on body weight loss during BLM-induced lung fibrosis. Chrna ${ }^{+/+}$and $C h r n a 7^{-/}$mice were intratracheally challenged with BLM $(3 \mathrm{mg} / \mathrm{kg})$ and $C h r n a 7^{+/+}$mice receiving intratracheal saline were used as control. Body weight was followed for $7 \mathrm{~d}$. " $p<0.05$ for BLM-challenged Chrnat/- versus BLM-challenged Chrna $7^{+/+}$mice. (B, C) Effect of $\alpha 7$ nAChR on BAL profiles during BLM-induced lung fibrosis. Experimental protocol was the same as Figure $1 \mathrm{~A}$. At $7 \mathrm{~d}$, mice were euthanized and BAL was performed to measure (B) leukocytes and (C) proteins levels. The data were pooled from two independent experiments. $\mathrm{N}=6$ - 15 in each group. " $\mathrm{p}<0.05$ for BLM-challenged Chrnat $7^{--}$versus BLM-challenged Chrna7 ${ }^{+/+}$mice. (D-H) Effect of $\alpha 7 \mathrm{nAChR}$ on blood profiles during BLM-induced lung fibrosis. Experimental protocol was the same as Figure $1 \mathrm{~A}$. At $7 \mathrm{~d}$, mice were euthanized and peripheral blood was collected to measure (D) monocytes, (E) eosinophils, (F) neutrophils, (G) lymphocytes and (H) hematocrit. $\mathrm{N}=4$. " $p<0.05$ for BLM-challenged Chrna $7^{/-}$versus BLM-challenged Chrnat ${ }^{+/+}$mice. (I-J) Effect of $\alpha 7$ nAChR on percentage of lung acetylcholine-producing CD4 ${ }^{+}$lymphocytes in the early stage of BLM-induced lung fibrosis. Experimental protocol was the same as Figure 1A. At $7 \mathrm{~d}$, mice were euthanized and lungs were removed and homogenized for isolating cells. The cells were submitted to flow cytometry to analyze $\mathrm{CD} 4^{+} \mathrm{CHAT}{ }^{+}$cells. The whole cell population of digested lung cells was used for analysis after excluding doublets or dead cells. The percentage of $\mathrm{CD}^{+} \mathrm{CHAT}^{+}$cells is shown. $\mathrm{N}=4$. " $p<0.01$ for saline-challenged Chrnat ${ }^{+/+}$versus BLM-challenged $\mathrm{Chrna}^{+/+}$mice. Data are mean $\pm \mathrm{SD}$.

Lung Arg1 was elevated in BLMchallenged wild-type mice, whereas this gene was attenuated by deletion of Chrna7. Deletion of Chrna7 did not affect Il1 $\beta, T n f \alpha, I l 4, I l 33$ or Il6 at mRNA levels in BLM-challenged lung (data not shown). These findings suggest that $\alpha 7$ $\mathrm{nAChR}$ makes a greater contribution to the regulation of fibrosis-related genes and Arg1 than proinflammatory genes in the early stage of BLM-induced lung fibrosis.

\section{Deficiency of $\alpha 7$ nAChR Prevents Body-weight Loss and Reduces Lung Profibrotic Genes during the Development of BLM-Induced Lung Fibrosis}

To further observe whether deletion of Chrna7 affects the development of BLM-induced lung fibrosis, we challenged the mice intratracheally with a middle dose of $1.5 \mathrm{mg} / \mathrm{kg}$ BLM. Under this dosage, mice survived after $14 \mathrm{~d}$. BLM-challenged Chrna $7^{-/}$mice were resistant to body-weight loss compared to BLM-challenged Chrna7 ${ }^{+/+}$mice (Figure 3A; initial body weights: wildtype, $25.3 \pm 1.4 \mathrm{~g}$, Chrna7 ${ }^{--} 27.4 \pm 2.6 \mathrm{~g}$ ) . Deletion of Chrna7 could reduce expression of lung profibrotic genes Col1a1, Fsp1 and Fstl1 (7) (Figures 3C, D). We also measured the inflammation-related genes Cxcl2, Mcp1 and Arg1 $14 \mathrm{~d}$ after BLM challenge. Lung Cxcl2, Mcp1 and Arg1 were increased in BLM-challenged wild-type mice (Figures 3E-G). 

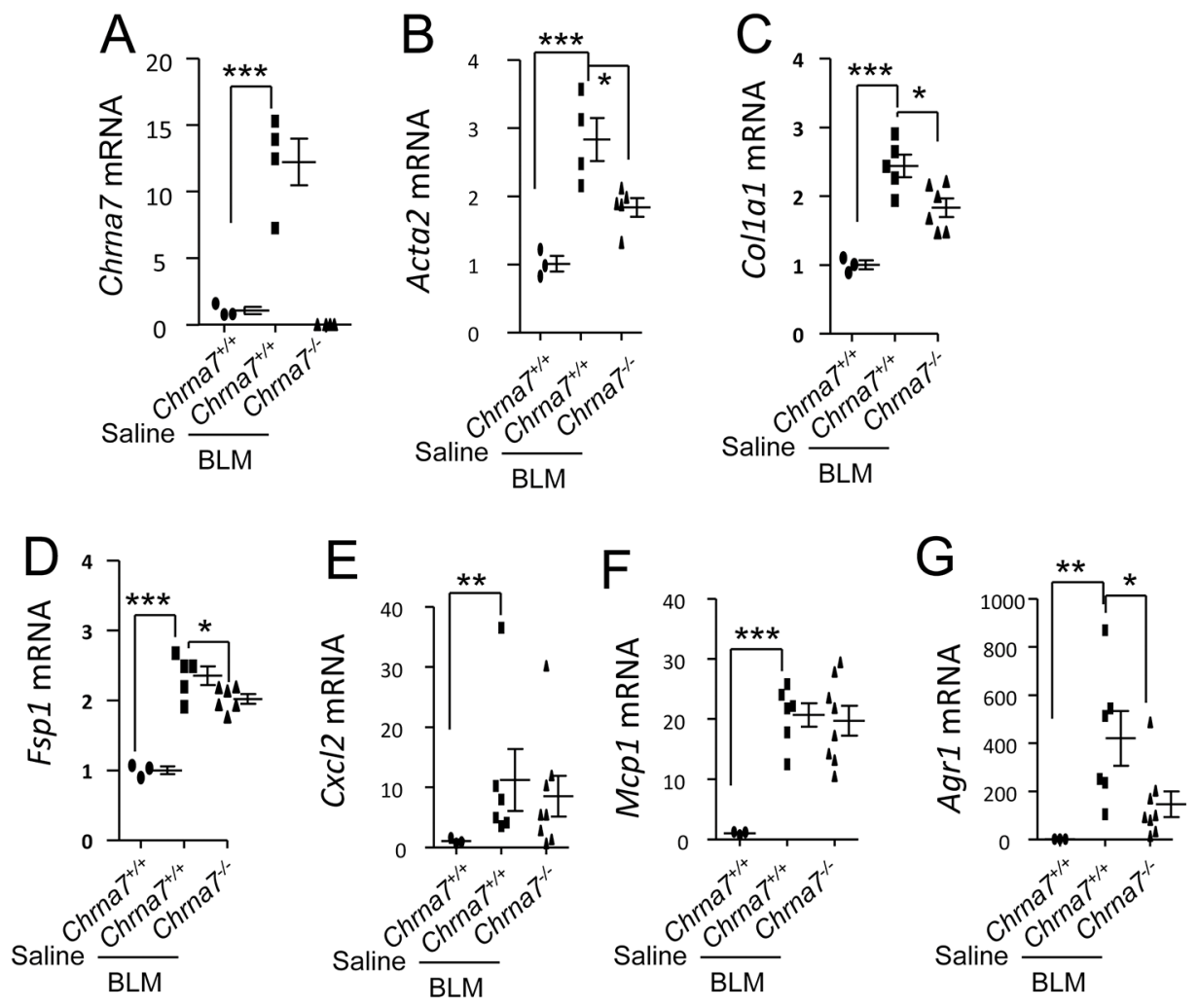

Figure 2. Effect $\alpha 7 \mathrm{nAChR}$ on expression of lung fibrogenic and proinflammatory genes in the early stage of BLM-induced lung fibrosis. (A) $\alpha 7 \mathrm{nAChR}$ expression at mRNA levels in the early stage of BLM-induced lung fibrosis. Chrnat $7^{+/+}$and $\mathrm{Chrna}^{/ /}$mice were intratracheally challenged with BLM (3 $\mathrm{mg} / \mathrm{kg}$ ) and $\mathrm{Chrna}^{+/+}$mice receiving intratracheal saline were used as control. The mice were killed at $7 \mathrm{~d}$ to measure Chrna7 expression. "* $p<0.001$ for BLM-challenged Chrna $7^{+/+}$versus saline-challenged Chrna7 ${ }^{+/+}$mice. (B-D) Effect of $\alpha 7 \mathrm{nAChR}$ lung fibrogenic genes in the early stage of BLM-induced lung fibrosis. Experimental protocol was the same as Figure 2A. The mice were killed at $7 \mathrm{~d}$ and the lungs were homogenized for extracting RNA to measure (B) Acta2, (C) Collal and (D)

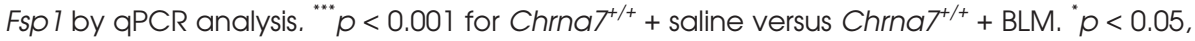
" $p<0.05$ for BLM-challenged Chrna $7^{-/}$versus BLM-challenged Chrnat ${ }^{+/+}$mice. (E-G) Effect of $\alpha 7 \mathrm{nAChR}$ on lung inflammatory genes ( $\mathrm{CXCl} 2, \mathrm{Mcp} 7$ and Arg 7 ) in the early stage of $\mathrm{BLM}$-induced lung fibrosis. Experimental protocol was the same as Figures $2 \mathrm{~B}-\mathrm{D}$. The lungs were homogenized for extracting RNA to measure (E) CxCl2, (F) Mcpl and (G) Argl by qPCR analysis. $N=3-8$ in each group. " " $p<0.001$ for $\mathrm{Chrna}^{+/+}+$saline versus $\mathrm{Chrna}^{+/+}+$ BLM. $p<0.05$ for BLM-challenged Chrna $7^{-/}$versus BLM-challenged Chrna $7^{+/+}$mice. Data are mean $\pm S D$.

Lung Cxcl2 and Mcp1 were not different between BLM-challenged wild-type and Chrna7 knockout mice (Figures 3E, F). But lung Arg1 showed a trend of reduction in BLM-challenged wild-type mice compared to BLM-challenged Chrna7 knockout mice (Figure 3G). These findings confirm that $\alpha 7 \mathrm{nAChR}$ plays an important role in regulating fibrosis-related genes rather than proinflammatory genes during BLM-induced lung inflammation and fibrosis.

\section{Deletion of Chrna7 Lessens Lung Ashcroft Score and Consolidation during the Development of BLM- Induced Lung Fibrosis}

Using the same experimental setting as in Figure 3, we collected lungs to examine histology. Using the Ashcroft scoring system, we qualitatively analyzed the severity of lung fibrotic lesions. Representative microphotographs of histology are shown in Figures 4A-C. Large contiguous fibrotic masses, air bubbles and fibrous obliteration were found in the BLM-challenged wild-type mice compared to BLM-challenged $\alpha 7$ nAChR knockout mice (Figures 4B, C). Quantitatively, the Ashcroft score in the BLM-challenged $\alpha 7 \mathrm{nAChR}$ knockout mice was greater than in the BLMchallenged wild-type mice (Figure 4D). Aerated lung area was significantly reduced in BLM-challenged wild-type mice, but this change was reversed by deletion of Chrna7 (Figure 4E), suggesting that $\alpha 7 \mathrm{nAChR}$ contributes to lung architecture destruction during the development of lung fibrosis.

Under this experiment condition, we also performed Masson's trichrome staining of the lung. Representative microphotographs are shown in Figures 4F-H. With this staining technique, mature collagen stains blue. Blue staining in the lung, including alveolar septa or interstitium and peribronchial connective tissue, was more prominent in BLM-challenged wild-type mice compared to BLMchallenged $\alpha 7 \mathrm{nAChR}$ knockout mice (Figures 4G, H). As seen by Image-Pro Plus software analysis, blue-stained areas (Figure 4I) and mean optical density of blue-stained areas (Figure 4J) were significantly increased in BLM-challenged wild-type mice compared to BLMchallenged $\alpha 7 \mathrm{nAChR}$ knockout mice.

\section{Deletion of Chrna7 Attenuates Area and Optical Density of Masson's Trichrome Staining in BLM-Induced Lung Fibrosis}

We challenged Chrna7 ${ }^{+/+}$and Chrna $7^{-/}$mice with a low dose of BLM $(0.5 \mathrm{mg} / \mathrm{kg})$ intratracheally. Chrna ${ }^{+/+}$ mice received saline intratracheally as controls. At $21 \mathrm{~d}$, the lungs were collected for Masson's trichrome staining. As seen in Figure $4 \mathrm{~F}-\mathrm{H}$, blue staining in the lung, including alveolar septa or interstitium and peribronchial connective tissue, was increased in BLM-challenged 

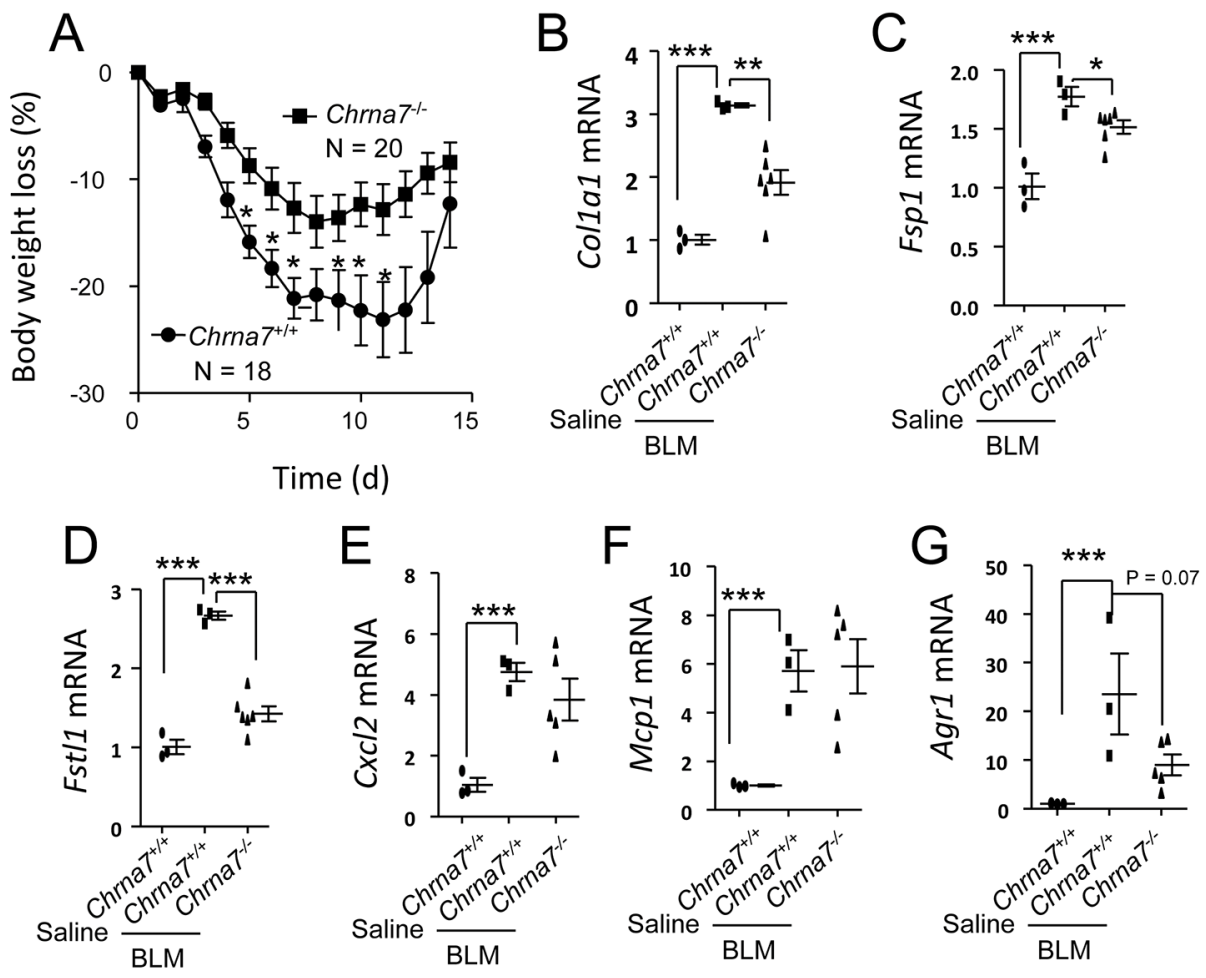

Figure 3. Effect of $\alpha 7 \mathrm{nAChR}$ on body-weight loss, lung fibrogenic and proinflammatory genes during the development of BLM-induced lung fibrosis. (A) Effect $\alpha 7 \mathrm{nAChR}$ on body-weight loss during the development of BLM-induced lung fibrosis. Chrna $7^{+/+}$and Chrna $7^{-1}$ mice were intratracheally challenged with BLM $(1.5 \mathrm{mg} / \mathrm{kg})$ and followed for 14 d. $\mathrm{N}=18-20$ in each group. " $p<0.05$ for $\mathrm{Chrnat}^{+/+}$versus $\mathrm{Chrnat}^{/-}$mice receiving intratracheal BLM. Data are mean $\pm S D$. (B-D) Effect of $\alpha 7 n A C h R$ on lung fibrogenic genes during the development of BLM-induced lung fibrosis. Experimental protocol was the same as Figure $3 \mathrm{~A}$. The mice were euthanized at $7 \mathrm{~d}$ and the lungs were homogenized for extracting RNA to measure (B) Colla l, (C) Fspl and (D) Fstll by qPCR analysis. N = 3-6 in each group. " $p<0.05, " p<0.01, " ' p<0.001$ in each gene comparison for Chrna $7^{+/+}$ versus Chrnat'- mice receiving intratracheal BLM. (E-G) Effect of $\alpha 7 \mathrm{nAChR}$ on lung proinflammatory genes during the development of BLM-induced lung fibrosis. Experimental protocol was the same as Figures $2 B-D$. The lungs were homogenized for extracting RNA to measure (E) CxCl2, (F) Mcp 1 and (G) Arg 1 by qPCR analysis. N = 3-5 in each group. ${ }^{\cdots *} p<0.001$ in each gene comparison for $\mathrm{Chrna}^{+/+}$versus $\mathrm{Chrna7}^{-/-}$mice receiving intratracheal BLM. Data are mean $\pm S D$.

wild-type mice compared to BLMchallenged $\alpha 7 \mathrm{nAChR}$ knockout mice (Figures 5A-C). Ashcroft scores were significantly reduced in BLM-challenged $\alpha 7 \mathrm{nAChR}$ knockout mice compared to BLM-challenged wild-type mice (Figure 5D). Using Image-Pro Plus software, we analyzed blue-stained areas (Figure 5E) and mean optical density in blue-stained areas (Figure 5F). Both parameters were reduced in BLMchallenged $\alpha 7 \mathrm{nAChR}$ knockout lungs relative to BLM-challenged wild-type lungs. These findings support that $\alpha 7$ nAChR contributes to collagen deposition in BLM-induced lung fibrosis.

\section{Deletion of Chrna 7 Reduces Lung Arginase $~^{+}$Ly $6 \mathrm{C}^{+}$Cells in the Early Stage of Bleomycin-Induced Lung Fibrosis}

We challenged the mice with a low dose of BLM $(0.5 \mathrm{mg} / \mathrm{kg})$ intratracheally to test whether deficiency of $\alpha 7 \mathrm{nAChR}$ would affect BAL profiles and M2 macrophage activation in the early phage of BLM-induced lung fibrosis. BAL leukocytes and protein levels were increased $7 \mathrm{~d}$ after BLM challenge, but deletion of Chrna7 did not affect these parameters (Figures 6A, B). Considering that alternative macrophage activation would play an important role in mediating lung fibrosis, we used flow cytometry to analyze lung arginase $1^{+} \mathrm{Ly} 6 \mathrm{C}^{+}$cells (monocytes) from the digested lungs. We found that these cells were increased in BLM-challenged $\mathrm{Chrna}^{+/+}$mice $7 \mathrm{~d}$ after BLM challenge. Deletion of Chrna7 reduced lung arginase $1^{+} \mathrm{Ly} 6 \mathrm{C}^{+}$cells, suggesting that $\alpha 7 \mathrm{nAChR}$ mediates alternative macrophage activation in the early stage of BLM-induced lung fibrosis (Figures 6C, D).

\section{Deletion of Chrna 7 Attenuates Lung Fibrosis but Does Not Affect Inflammatory Mediators at Low Dose}

Mice were challenged with the low dose of BLM intratracheally and followed for $21 \mathrm{~d}$. BAL protein levels, total cell counts, neutrophils and monocytes were not different between BLMchallenged Chrna $7^{+/+}$and Chrna $7^{-/}$mice (Figures 7A-E). Body-weight loss in BLM-challenged Chrna ${ }^{-/}$mice was reduced compared to BLM-challenged $\mathrm{Chrna7}^{+/+}$mice (Figure 7F; initial body weights: wild-type, $24.8 \pm 1.4 \mathrm{~g}$. Chrna7 ${ }^{-1}$ $25.9 \pm 1.5 \mathrm{~g}$ ). At $21 \mathrm{~d}$, hydroxyproline in the supernatant of lung homogenate in BLM-challenged Chrna $7^{+/+}$mice was increased, whereas deletion of Chrna7 mice could significantly reduce this change (Figure 7G). Lung TGF- $\beta$ levels in BLM-challenged Chrna7 ${ }^{+/+}$mice were elevated. There was no difference in lung TGF- $\beta$ levels between BLM-challenged Chrna $^{+/+}$and Chrna7 $7^{-/}$mice (Figure $7 \mathrm{H}$ ). Expression of $\alpha$-SMA at protein levels was higher in BLM-challenged Chrna7 $7^{+/+}$ mice than saline-challenged $\mathrm{Chrna}^{+/+}$ mice; however, deficiency of $\alpha 7 \mathrm{nAChR}$ significantly reduced $\alpha$-SMA expression (Figures 7I, J). Lung Acta2 mRNA levels were reduced in BLM-challenged Chrna7 ${ }^{-/}$ mice compared to Chrna $7^{+/+}$mice 

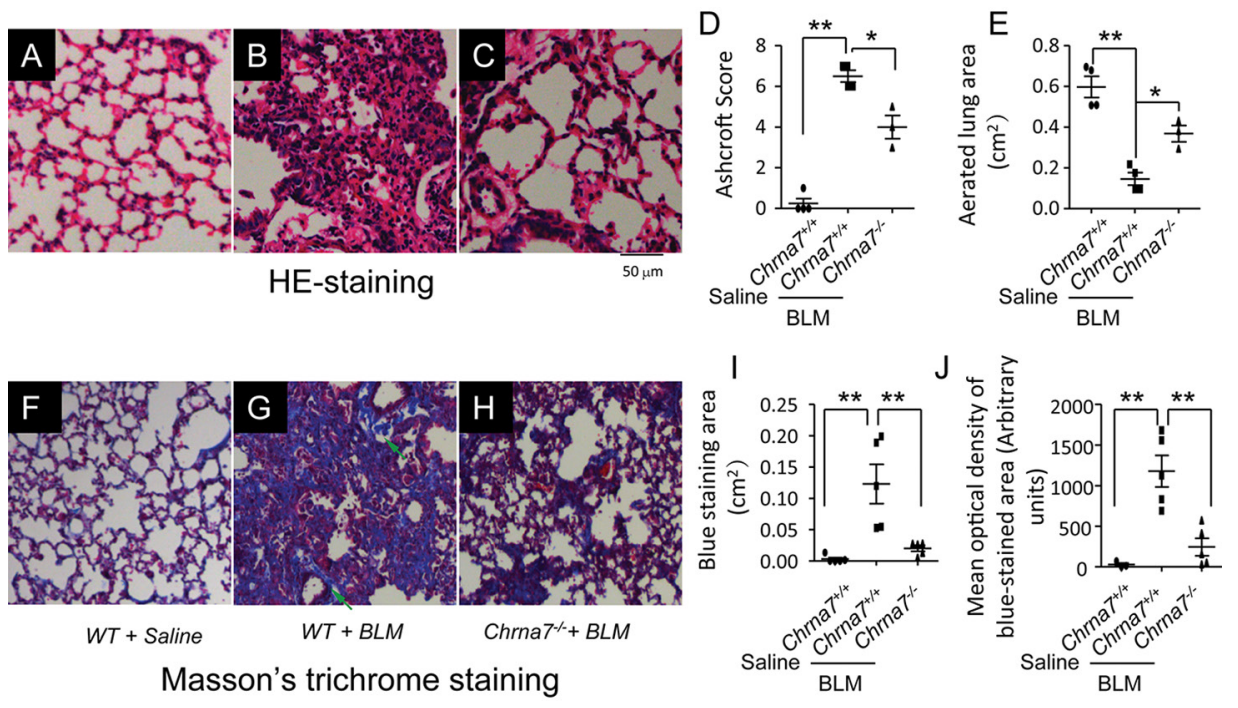

Figure 4. Qualitative and quantitative analysis of lung histology and Masson's trichrome staining during BLM-induced lung fibrosis. (A-C) Representative microphotographs of lung histology. Chrnat $7^{+/}$and Chrna $7^{-/}$mice were intratracheally challenged with BLM $\left(1.5 \mathrm{mg} / \mathrm{kg}\right.$ ) and euthanized at $14 \mathrm{~d}$. Saline-challenged Chrna $7^{+/}$mice were used as control. The lungs were removed for H\&E staining. (A) Chrnat $7^{+/+}+$saline, (B) Chrna7 $7^{+/}+$BLM and (C) Chrna7 ${ }^{-1}+$ BLM. Objective magnification $\times 20$, bar $50 \mu \mathrm{m}$. (D, E) Qualitative and quantitative analysis of lung histology. (D) Qualitative analysis of histology by Ashcroft scoring system. (E) Measurements of aerated lung area by Image-Pro Plus software. $\mathrm{N}=3-4$ in each group. " $p<0.01$ and $" p<0.05$ in each comparison. Data are mean $\pm \mathrm{SD}$. $(\mathrm{F}-\mathrm{H})$ Representative microphotographs of Masson's trichrome staining. Chrna7 $7^{+/}$and Chrna $7^{--}$mice were intratracheally challenged with BLM $(1.5 \mathrm{mg} / \mathrm{kg})$ and euthanized at $14 \mathrm{~d}$. Saline-challenged Chrna $7^{+/+}$mice were used as control. The lungs were removed for Masson's trichrome staining. Green arrows indicate positive peribronchial and interstitial staining. Objective magnification $\times 20$, bar $50 \mu \mathrm{m}$.

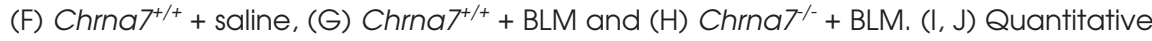
analysis of Masson's trichrome staining. (I) Measurements of blue-stained area. (J) Measurements of mean optical density of blue-stained area by Image-Pro Plus software. $N=5$ in each group. $" p<0.01$ in compared groups. Data are mean $\pm S D$.

(Figure 7K); however, lung Il6, Mcp1 and Cxcl2 mRNA levels were not different between BLM-challenged $\mathrm{Chrna7}^{+/+}$and Chrna $7^{-1}$ mice (Figures 7L-N). These findings suggest that $\alpha 7 \mathrm{nAChR}$ coupled with TGF- $\beta$ signaling contributes to the pathogenesis of BLM-induced lung fibrosis.

\section{Activation of $\alpha 7$ nAChR Promotes Transcription of Fibrotic Genes by Boosting TGF- $\beta$ Signaling}

The MRC5 cell line has been used for studying TGF- $\beta$ signaling and fibrosis (47-51). The A549 cell line is frequently used in research regarding alveolar type II epithelial cells (52-55). Therefore, we used these two cell lines to study whether activation of $\alpha 7 \mathrm{nAChR}$ would promote transcription of fibrotic genes by boosting TGF- $\beta$ signaling. Using fluor633 $\alpha$-BTX (a specific antagonist of $\alpha 7 \mathrm{nAChR}$ ) labeling, we found that fibroblasts expressed $\alpha 7 \mathrm{nAChR}$ (Figure 8A). To investigate whether activation of $\alpha 7$ nAChR influences expression of Acta2 (an early marker of fibrogenesis), we pretreated the fibroblasts or A549 cells (expressing $\alpha 7 \mathrm{nAChR}$ ) (56) with $\alpha 7$ nAChR agonist GTS-21 and then challenged these cells with BLM $(10 \mu \mathrm{M})$. The cells were harvested $24 \mathrm{~h}$ after BLM to analyze Acta2 expression. In fibroblasts, BLM reduced Acta2 expression and pretreatment with GTS-21 brought it back to baseline (Figure 8B). In A549 cells, BLM challenge increased Acta2 expression by more than three-fold, but GTS-21 had no effect (Figure 8C). We then used rhTGF- $\beta 1$ to repeat the above experiments. In A549 cells, rhTGF- $\beta 1$ stimulation increased expression of Acta2, but in combination with GTS-21 had no effect (Figure 8C). In lung fibroblasts, rhTGF- $\beta 1$ stimulation upregulated expression of Acta2, and this effect can be boosted by combination with GTS-21 (Figures 8D, E).

We further studied whether activation of $\alpha 7 \mathrm{nAChR}$ augments TGF- $\beta$ signaling. We collected GTS-21 pretreated fibroblasts with or without rhTGF- $\beta 1$ challenge for immunoblotting analysis. TGF- $\beta 1$ induced phosphorylation of Samd2/3, and expression of $\alpha$-SMA was augmented by GTS-21 (Figure 8F). Moreover, GTS-21 further augmented rhTGF- $\beta 1$-triggered phosphorylation of PTP1B, a known contributor to fibrogenesis (57) (Figure 8F). These findings suggest that activation of $\alpha 7 \mathrm{nAChR}$ could enhance transcription of fibrogenic genes by boosting TGF- $\beta$ signaling.

\section{Dose-dependent Effect of GTS-21 on rhTGF- $\beta 1$-Induced Fibrogenic Genes and Signaling}

We pretreated the fibroblasts with different concentrations of GTS-21 $(0,6.25,12.5$ and $25 \mu \mathrm{M}) 30 \mathrm{~min}$ prior to rhTGF- $\beta 1$ stimulation ( $5 \mathrm{ng} / \mathrm{mL}$ ) to confirm whether activation of $\alpha 7 \mathrm{nAChR}$ could boost TGF- $\beta 1$ signaling and transcription of fibrogenic genes. At $24 \mathrm{~h}$, rhTGF- $\beta 1$ stimulation increased expression of Acta2, Col1a1 and Fstl1; addition of GTS-21 (25 $\mu \mathrm{M})$ further upregulated these genes (Figures 9A-C). rhTGF- $\beta 1$ alone did not increase Fsp1 mRNA, but in combination with GTS-21 $(25 \mu \mathrm{M})$ could upregulate it (Figure 9D). At protein levels, pretreatment with GTS-21 markedly increased rhTGF- $\beta 1$-triggered expression of p-PTP1B, p-Samd2/3, collagen 1 and $\alpha$-SMA (Figure 9E). These findings support that $\alpha 7 \mathrm{nAChR}$ is an important regulator of TGF- $\beta$ signaling in fibroblasts. 


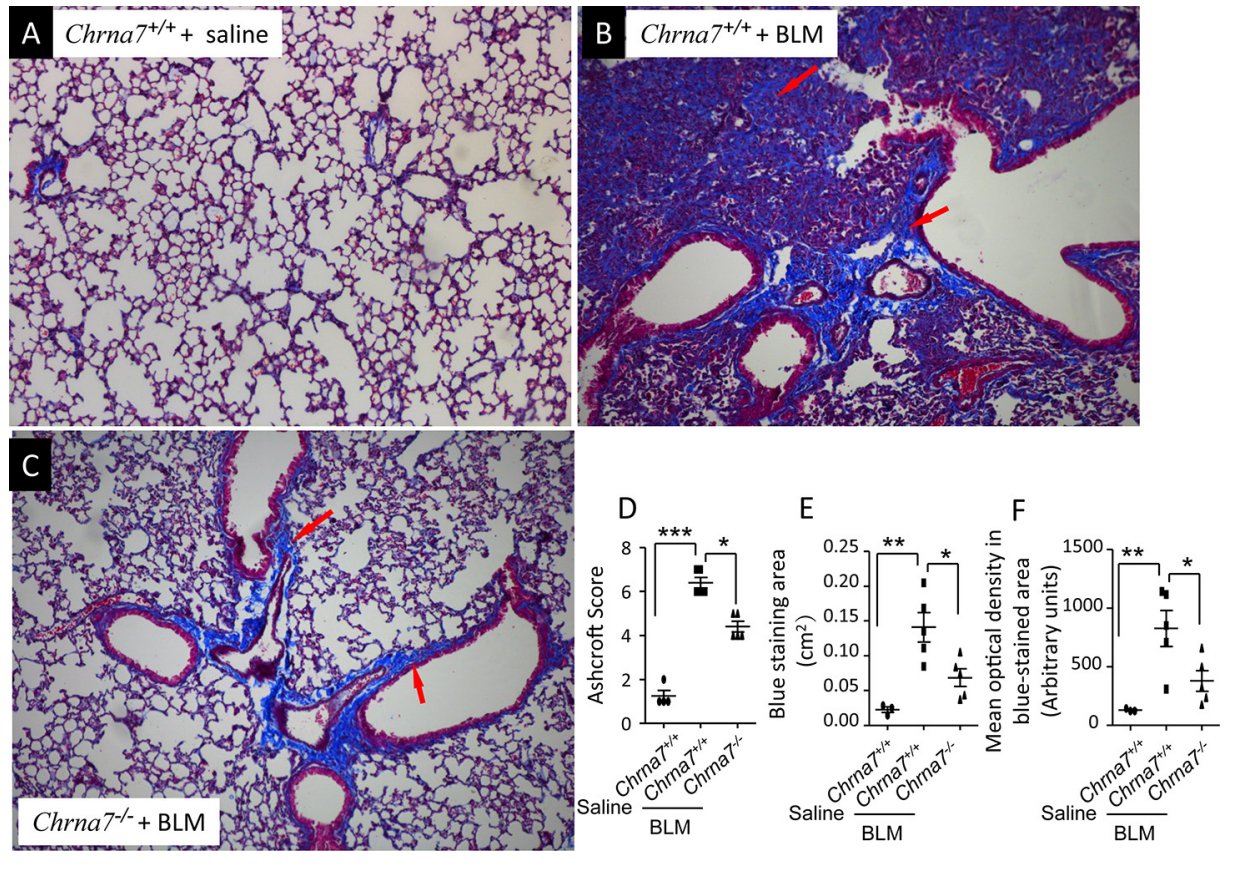

Figure 5. Qualitative and quantitative analysis of Masson's trichrome staining in established BLM-induced lung fibrosis. (A-C) Representative microphotographs of Masson's trichrome staining. Chrna $7^{+/+}$and $C h r n a 7^{-/}$mice were intratracheally challenged with BLM $(0.5 \mathrm{mg} / \mathrm{kg})$ and euthanized at $21 \mathrm{~d}$. Saline-challenged Chrnat ${ }^{+/+}$mice were used

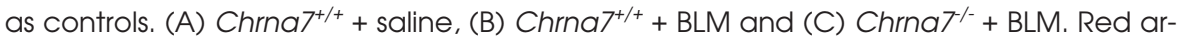
rows indicate positive peribronchial and interstitial staining. Objective magnification was $\times$ 10. (D-F) Qualitative and quantitative analysis of Masson's trichrome staining by Image-Pro Plus software. (D) Analysis of severity of fibrotic lesions by Ashcroft scoring system. (E) Measurements of trichrome staining positive area. (F) Measurements of mean optical density in blue-stained area. $N=4-5$ in each group. " $p<0.001 " ~ p<0.01$, and " $p<0.05$ in each comparison. Data are mean \pm SD.
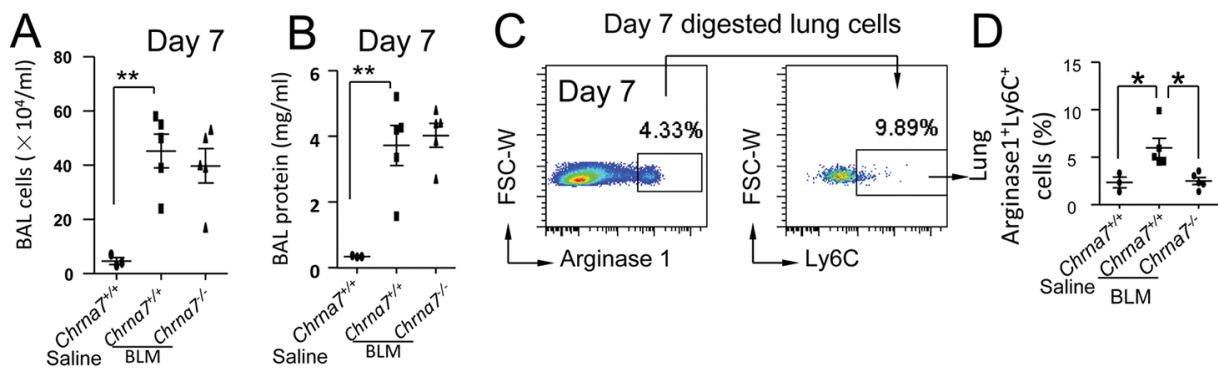

Figure 6. Changes of BAL profiles and lung arginase $1^{+} \mathrm{Ly} 6 \mathrm{C}^{+}$cells at $\mathrm{d} 7 \mathrm{with}$ lowdose BLM challenge. (A, B) BAL leukocytes and protein levels at $d 7$ with low-dose BLM challenge. Chrna $7^{+/+}$and Chrnat/- mice were intratracheally challenged with BLM $(0.5 \mathrm{mg} / \mathrm{kg})$ and euthanized at $\mathrm{d} 7$. Saline-challenged Chrna ${ }^{+/+}$mice were used as controls. $N=3-5$. " $p<0.01$ in compared groups. (C, D) Flow cytometry analysis of lung

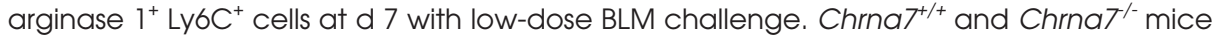
were intratracheally challenged with BLM $(0.5 \mathrm{mg} / \mathrm{kg})$ and euthanized at $\mathrm{d} 7 \mathrm{~d}$. Salinechallenged Chrna $7^{+/}$mice were used as controls. The lung cells were isolated by digestion. The cells in the whole cell gate were analyzed by Flowjo software. The percentage of arginase $1^{+} \mathrm{Ly}_{6} \mathrm{C}^{+}$cells is shown. $\mathrm{N}=3-5$. $" \mathrm{p}<0.05$ between compared groups.
The Regulatory Effect of $\alpha 7 \mathrm{nAChR}$ on TGF- $\beta$ Signaling Depends on PTPIB

It has been reported that PTP1B deficiency confers resistance to TGF- $\beta$ through Smad inhibition in hepatocytes (57). We silenced Ptpn1 by infecting the fibroblasts with pLKO.1 shRNA-Ptpn1 lentivirus and repeated the experiment (shown in Figures 8-9) to clarify whether $\alpha 7 \mathrm{nAChR}$ regulates TGF- $\beta$ signaling via PTP1B. We found that Ptpn1 was efficiently silenced and rhTGF- $\beta 1$ alone or combined with GTS-21 did not alter Ptpn1 expression (Figure 10A). GTS-21 increased rhTGF- $\beta 1$-triggered expression of Col1a1 and Acta2 expression in a dose-dependent manner in the control group, and this change could be abolished by silencing Ptpn1 (Figures 10B, C). At protein levels, GTS- 21 boosted rhTGF- $\beta 1$-triggered expression of p-PTP1B, p-Smad2/3, $\alpha$-SMA and collagen 1 dose-dependently; however, silencing Ptpn1 with $p L K O .1$ shRNA-Ptpn1 lentivirus in fibroblasts abolished these effects (Figure 10D). These findings suggest that $\alpha 7 \mathrm{nAChR}$ regulates TGF- $\beta$ signaling and fibrogenic gene transcription via PTP1B in fibroblasts.

\section{Deletion of Chrna7 Abolishes TGF- $\beta 1$-Induced Profibrotic Gene Transcription in Isolated Mouse Lung Primary Fibroblasts}

$\mathrm{Chrna7}^{+/+}$and $\mathrm{Chrna7}^{-/-}$mouse lung primary fibroblasts were isolated and confirmed by collagen 1 positive staining (Figure 11A). The cells were subjected to fluor633- $\alpha$ BTX staining and flow cytometry. About $61.4 \%$ of these cells were $\alpha 7 \mathrm{nAChR}$ positive (Figure 11B). In response to rmTGF- $\beta 1$ stimulation, Fstl1, Acta2 and Col1a1 at mRNA levels were increased. Pretreatment of the mouse lung primary fibroblasts with $\alpha 7 \mathrm{nAChR}$ agonist GTS-21 at $25 \mu \mathrm{M}$ markedly boosted TGF- $\beta$-induced expression of Fstl1, Acta2 and Col1a1. The enhanced effect of $\alpha 7 \mathrm{nAChR}$ agonist GTS-21 on TGF- $\beta$-induced expression of Fstl1, Acta2 and Col1a1 was diminished by deletion of Chrna7 (Figures 11C-F). 

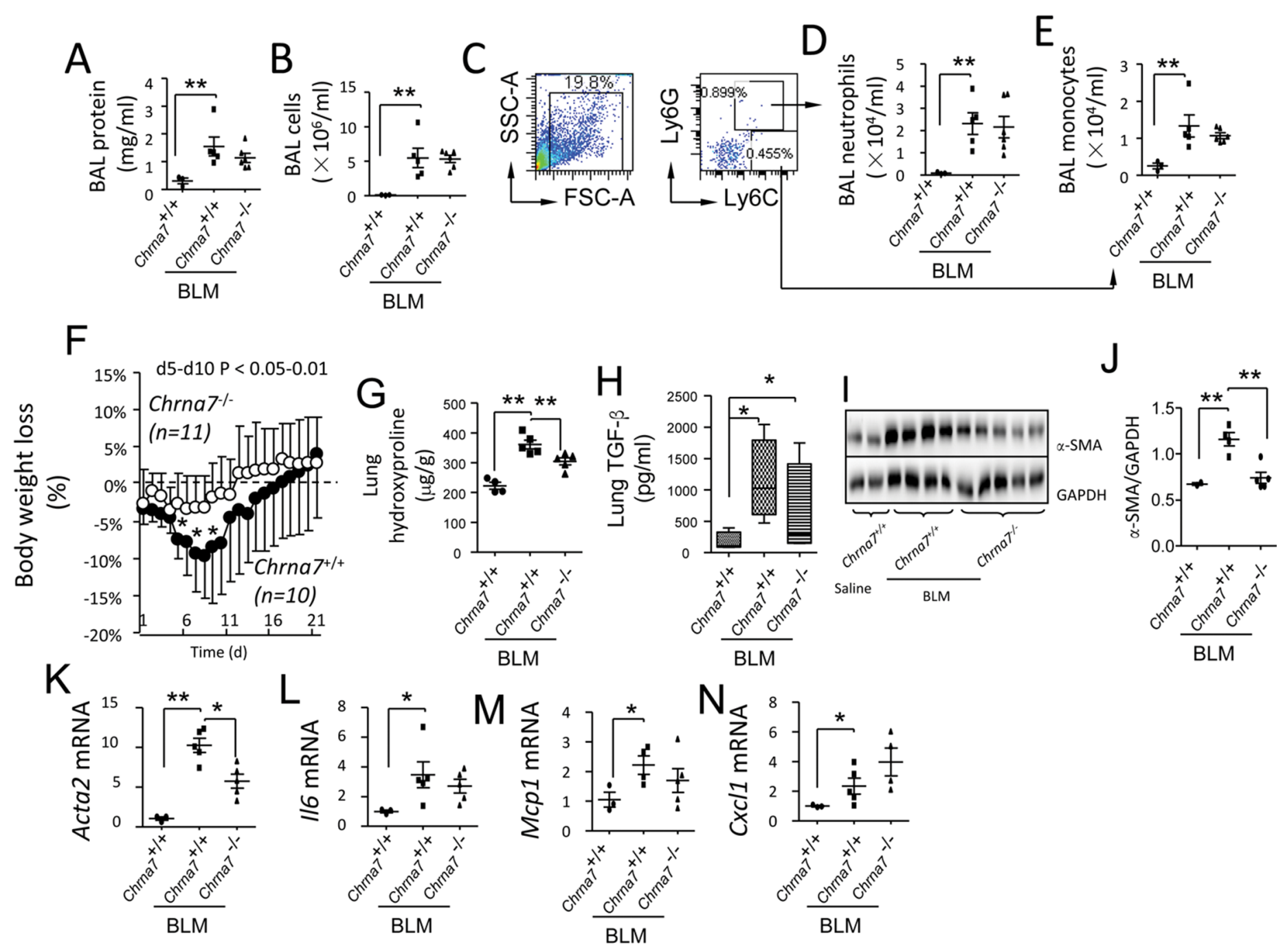

Figure 7. Deficiency of $\alpha 7 \mathrm{nAChR}$ reduced lung fibrosis but did not change lung inflammatory parameters. (A-E) Changes of BAL parameters and flow cytometry analysis of BAL monocytes and neutrophils. The mice were intratracheally challenged with BLM $(0.5 \mathrm{mg} / \mathrm{kg})$ and euthanized at $21 \mathrm{~d}$. BAL was collected to measure (A) protein levels and (B) cell counts. The BAL cells were also labeled with fluorescent anti-Ly6C and Ly6G antibodies. The whole cell population and percentage of $L y 6 C^{\text {low }} L y 6 G^{\text {hi }}$ neutrophils and Ly6C $C^{\text {hily}} 6 G^{\text {low }}$ monocytes was determined by flow cytometry. The number of neutrophils and monocytes in the BAL was calculated by multiplying the percentage of these two cell populations by total BAL cell counts. $N=3-5$ in each group. " $p<0.01$, tested by two-way ANOVA. (F) Deficiency of $\alpha 7 \mathrm{nAChR}$ prevents body-weight loss during bleomycin-induced lung fibrosis. The mice were intratracheally challenged with BLM $(0.5 \mathrm{mg} / \mathrm{kg})$ and body weight was followed for $21 \mathrm{~d}$. $\mathrm{N}=10-11$ in each group. Data were pooled from two independent experiments. " $p<0.05$, tested by two-way ANOVA. (G) Measurements of lung hydroxyproline levels in bleomycin-induced lung fibrosis. At $21 \mathrm{~d}$ after $0.5 \mathrm{mg} / \mathrm{kg}$ intratracheal challenge, the mice were euthanized and lungs were homogenized. The supernatant of lung homogenate was used to measure lung hydroxyproline levels. $N=4-5$ in each group. " $p<0.01$ in compared groups. $(H)$ Detection of lung TGF- $\beta$ levels in bleomycin-induced lung fibrosis. At $21 \mathrm{~d}$ after $0.5 \mathrm{mg} / \mathrm{kg}$ intratracheal challenge, the supernatant of lung homogenate was used to measure TGF- $\beta$ levels by ELISA. $N=4$ in each group. " $p<0.05$ in compared groups. (I, J) Western blotting analysis of $\alpha$-SMA in bleomycin-induced lung fibrosis. At $21 \mathrm{~d}$ after $0.5 \mathrm{mg} / \mathrm{kg}$ intratracheal challenge, the supernatant of lung homogenate was used to determine expression of $\alpha$-SMA by western blotting. (H) Western blotting bands in compared groups. (I) Ratio of expression of $\alpha$-SMA to GAPDH analyzed by Image J software. $N=2-5$ in each group. " $p<0.05$ in compared groups. Data are mean $\pm \mathrm{SD}$. $(\mathrm{K}-\mathrm{N})$ Changes of lung profibrotic and inflammatory genes in bleomycin-induced lung fibrosis. At $21 \mathrm{~d}$ after $0.5 \mathrm{mg} / \mathrm{kg}$ intratracheal challenge, lungs were removed and homogenized for extracting RNA. Lung Acta2, Il6, Mcp 1 and Cxcl2 mRNA were detected by real-time PCR. $N=3-5$ in each group. " $p<0.05$, " $p<0.01$ in compared groups. Data are mean \pm SD. 
A

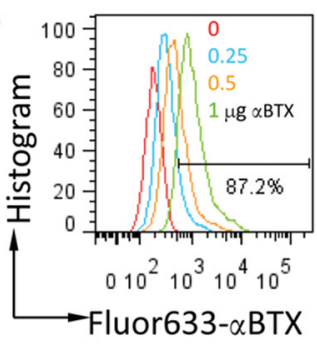

Bleomycin

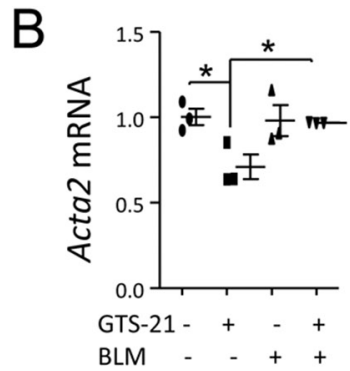

Fibroblast

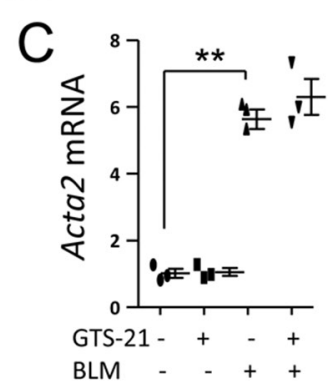

A549 cells

TGF- $\beta$
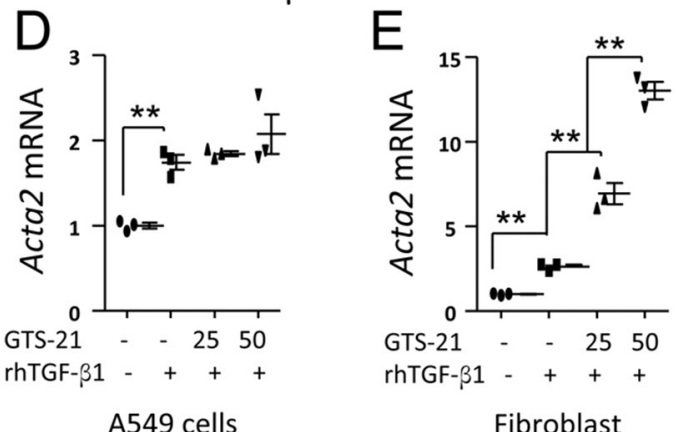

Fibroblast

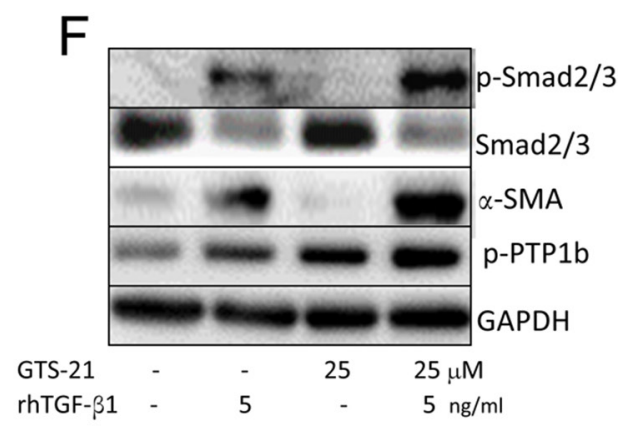

Figure 8. Activation of $\alpha 7 \mathrm{nAChR}$ enhances TGF- $\beta$ signaling. (A) Flow cytometry analysis of $\alpha 7 \mathrm{nAChR}$ expression in fibroblasts. The cells were collected and stained with fluor-633 $\alpha$-BTX at 0, 0.25, 0.5 and $1 \mu \mathrm{g} / \mathrm{mL}$. (B, C) Effect of GTS-21 on Acta2 in BLM-challenged fibroblasts and lung epithelial cells. The cells were pretreated with GTS-21 and then stimulated with or without BLM (10 $\mu$ M). (B) Changes of Acta2 mRNA in fibroblasts at $24 \mathrm{~h}$. (C) Acta2 mRNA expression in A549 cells at $24 \mathrm{~h}$. " $p<0.05$ for control and BLM-stimulated groups. $N=3$ in each group. (D, E) Effect of GTS-21 on Acta2 in rhTGF- $\beta 1$-challenged lung epithelial cells and fibroblasts. (D) Changes of Acta2 mRNA in A549 cells at $24 \mathrm{~h}$. (E) Changes of Acta2 mRNA in fibroblasts at $24 \mathrm{~h}$. The cells were pretreated with GTS-21 (25, $50 \mu \mathrm{M})$ and then stimulated with or without rhTGF- $\beta 1$ ( $5 \mathrm{ng} / \mathrm{mL})$. " $p<0.01$ for rhTGF- $\beta 1$ versus rhTGF- $\beta 1+G T S-21$ groups. $N=3$ in each group. Data are mean \pm SD. Experiments were repeated three times. (F) Immunoblotting analysis of activation of $\alpha 7 \mathrm{nAChR}$ on rhTGF- $\beta 1$-induced fibrogenic signaling. The cells were pretreated with GTS-21 ( $25 \mu \mathrm{M})$ and then stimulated with or without rhTGF- $\beta 1$ ( $5 \mathrm{ng} / \mathrm{mL}$ ). The cells were harvested after rhTGF- $\beta 1$ stimulation for detecting p-PTP1B, p-Smad2/3 and $\alpha$-SMA. Experiments were repeated three times.

These findings further support that activation of $\alpha 7 \mathrm{nAChR}$ contributes to fibrogenesis in fibroblasts.

\section{DISCUSSION}

Vagotomy reduced BLM-induced lung fibrosis (16), suggesting that acetylcholine acting on its receptor is required for the development of lung fibrosis. Here, for the first time we uncovered the mechanism that activation of acetylcholine receptor- $\alpha 7 \mathrm{nAChR}$ upregulates TGF- $\beta$ signaling, enhances transcription of profibrotic genes and promotes fibrogenesis in human fibroblasts. Deficiency of $\alpha 7 \mathrm{nAChR}$ dampened expression of lung profibrotic genes or proteins in a
BLM-induced lung fibrosis mouse model. In isolated mouse lung primary fibroblasts, deletion of Chrna7 diminished the TGF- $\beta$-upregulated transcription of profibrotic genes. These findings support that $\alpha 7 \mathrm{nAChR}$ is a key regulator of the development of lung fibrosis.

BLM-induced lung fibrosis is the most frequently used rodent model of lung fibrosis, and produces inflammatory and fibrotic events similar to those seen in human pulmonary fibrosis (58). In this study, to validate whether $\alpha 7 \mathrm{nAChR}$ had a profibrotic effect during BLM-induced lung fibrosis, we measured lung profibrotic genes and/or pathological parameters at different doses and euthanized the mice before death occurred. For example, high dose $3 \mathrm{mg} / \mathrm{kg}$, euthanized at $7 \mathrm{~d}$; middle dose $1.5 \mathrm{mg} / \mathrm{kg}$, euthanized at $14 \mathrm{~d}$; and low dose $0.5 \mathrm{mg} / \mathrm{kg}$, euthanized at $21 \mathrm{~d}$. These three conditions separately represent early, developing and advanced stages of BLM-induced lung fibrosis. By analyzing the findings from the different stages, the propagating role of $\alpha 7 \mathrm{nAChR}$ in BLM-induced lung fibrosis was proved.

It takes approximately $3 \mathrm{wks}$ to establish a mouse model of BLM-induced lung fibrosis $(59,60)$. The mice challenged with high-dose bleomycin usually died after $7 \mathrm{~d}$; therefore we had to euthanize mice by $7 \mathrm{~d}$. The first week is the early 

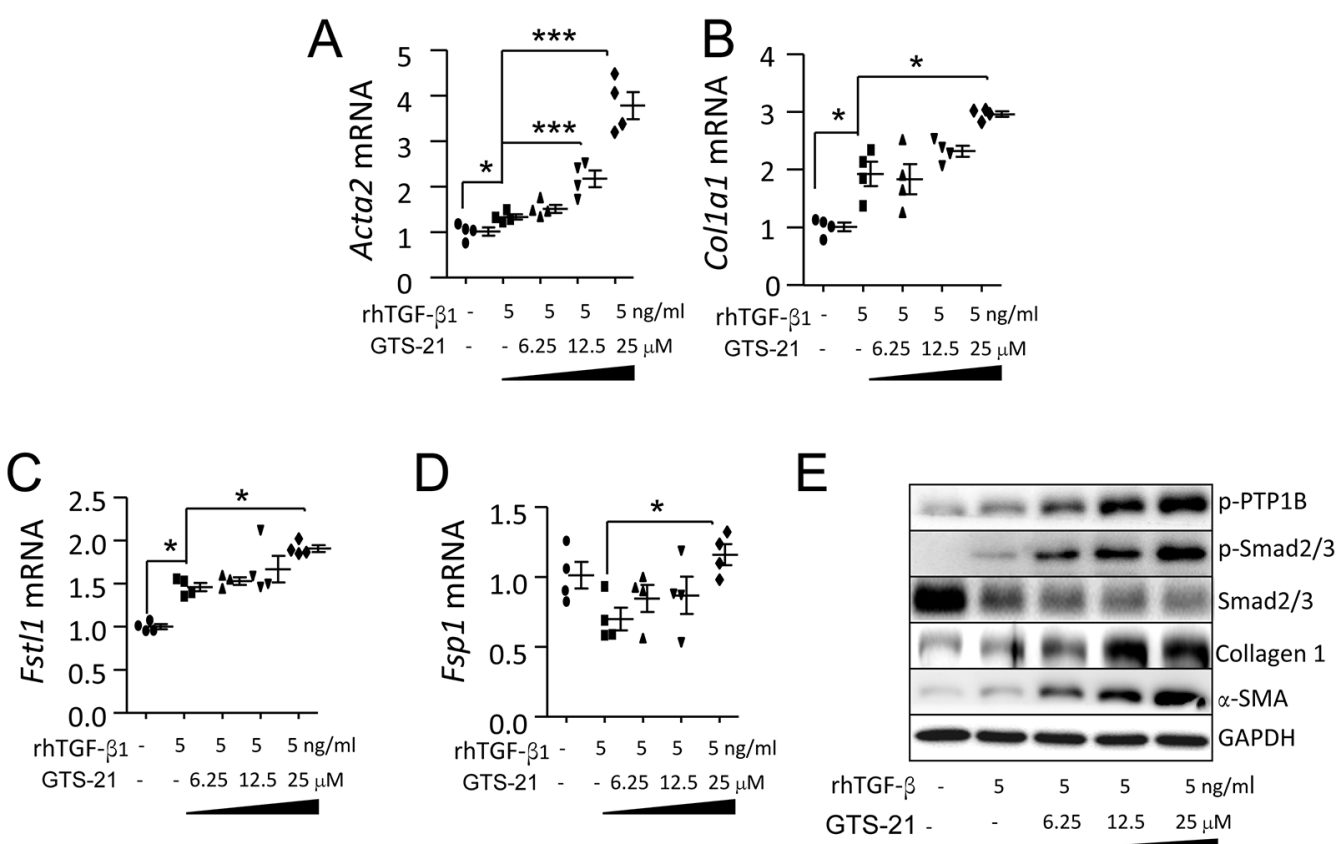

Figure 9. Dose-dependent effect of GTS-21 on rhTGF- $\beta 1$-induced fibrogenic genes and signaling. (A-D) Activation of $\alpha 7$ nAChR affects profibrotic genes in rhTGF- $\beta 1$-stimulated fibroblasts $24 \mathrm{~h}$ after rhTGF- $\beta 1$ challenge. The cells were pretreated with GTS-21 (6.25, 12.5 and $25 \mu \mathrm{M}$ separately; PBS was applied in control group) $30 \mathrm{~min}$ before stimulation with rhTGF- $\beta 1$ ( $5 \mathrm{ng} / \mathrm{mL}$ ). The cells were harvested $24 \mathrm{~h}$ after rhTGF- $\beta$ stimulation. (A) Acta2 mRNA. (B) Colla 1 mRNA. (C) Fstll mRNA. (D) Fsp 1 mRNA. " $p<0.05$, " $p<0.001$ rhTGF- $\beta 1$ versus rhTGF- $\beta 1+$ GTS-21 groups. $N=4$ in each group. Data are mean \pm SD. (E) Activation of $\alpha 7 \mathrm{nAChR}$ affects fibrogenic signaling in rhTGF- $\beta 1-$ stimulated fibroblasts. The fibroblasts were pretreated with GTS-21 at the indicated concentration 30 min before rhTGF- $\beta 1$ stimulation. The cells were collected $24 \mathrm{~h}$ after rhTGF- $\beta 1$ challenge to analyze TGF- $\beta$ signaling proteins $\mathrm{p}-\mathrm{PTP} 1 \mathrm{~B}, \mathrm{p}-\mathrm{Smad} 2 / 3, \alpha$-SMA and collagen 1 by immunoblotting. Experiments were repeated three times.

phase of BLM-induced lung fibrosis. During this stage, upregulation of profibrotic genes is required to develop lung fibrosis. We took this stage to detect the difference in proinflammatory and profibrotic genes between BLM-challenged wild-type and BLM-challenged $\alpha 7$ nAChR knockout mice. We found that deficiency of $\alpha 7 \mathrm{nAChR}$ reduced transcription of lung profibrotic genes (Figures 2B-D) but did not influence transcription of proinflammatory genes in the lung (Figures 2E, F). This finding indicates that inflammation was equivalent in BLM-challenged wild-type and $\alpha 7$ nAChR knockout mice, which could explain why deficiency of $\alpha 7 \mathrm{nAChR}$ did not affect BAL protein levels, an index of lung epithelial and endothelial permeability (Figure 1). We also found that levels of lung proinflammatory genes were comparable between BLM-challenged wild-type and BLM-challenged $\alpha 7$
nAChR knockout mice at $14 \mathrm{~d}$ during the development stage of lung fibrosis (Figure 3). At $21 \mathrm{~d}$, the advanced stage of lung fibrosis, BAL cells and protein levels were not different between these two groups (Figures 6A, B), but the severity of lung fibrosis in BLM-challenged $\alpha 7$ $\mathrm{nAChR}$ knockout mice was significantly lower (Figures 7G-K).

M2 macrophage activation has been implicated in the development of pulmonary fibrosis (61-63). Ly6 $\mathrm{C}^{\text {hi }}$ monocytes facilitate the progression of pulmonary fibrosis. Depletion of Ly6C ${ }^{\text {hi }}$ circulating monocytes reduced pulmonary fibrosis (62). In our study, we hypothesized that $\mathrm{Ly} \mathrm{C}^{+}$arginase $1^{+}$ cells were involved in alternative macrophage activation and contributed to lung fibrogenesis; therefore we analyzed this cell population in the digested lung cells and found that arginase $1^{+} \mathrm{Ly} 6 \mathrm{C}^{+}$ cells were significantly lower in the
BLM-challenged $\alpha 7 \mathrm{nAChR}$-deficient mice compared to BLM-challenged wildtype mice (Figures 6C, D). The findings support that $\alpha 7 \mathrm{nAChR}$ is implicated in the alternative activation macrophage and promotes lung fibrogenesis. The composition and function of the cell population in BAL and digested lung cells are different, which may explain why lack of $\alpha 7 \mathrm{nAChR}$ did not affect the BAL cell population (Figure 6A). In the lung, arginase 1 can be expressed by distal airway epithelial cells and endothelial cells besides alveolar macrophages (64-66). This may explain why more than $90 \%$ arginase $1^{+} \mathrm{Ly} 6 \mathrm{C}^{-}$cells were present, but their function is unknown.

In this study, the TGF- $\beta 1$ ELISA set was used to specifically measure mouse TGF $\beta 1$ protein levels in the supernatants of lung homogenates. We have not established a method to detect TGF- $\beta 1$ activity. However, we did find that deficiency 

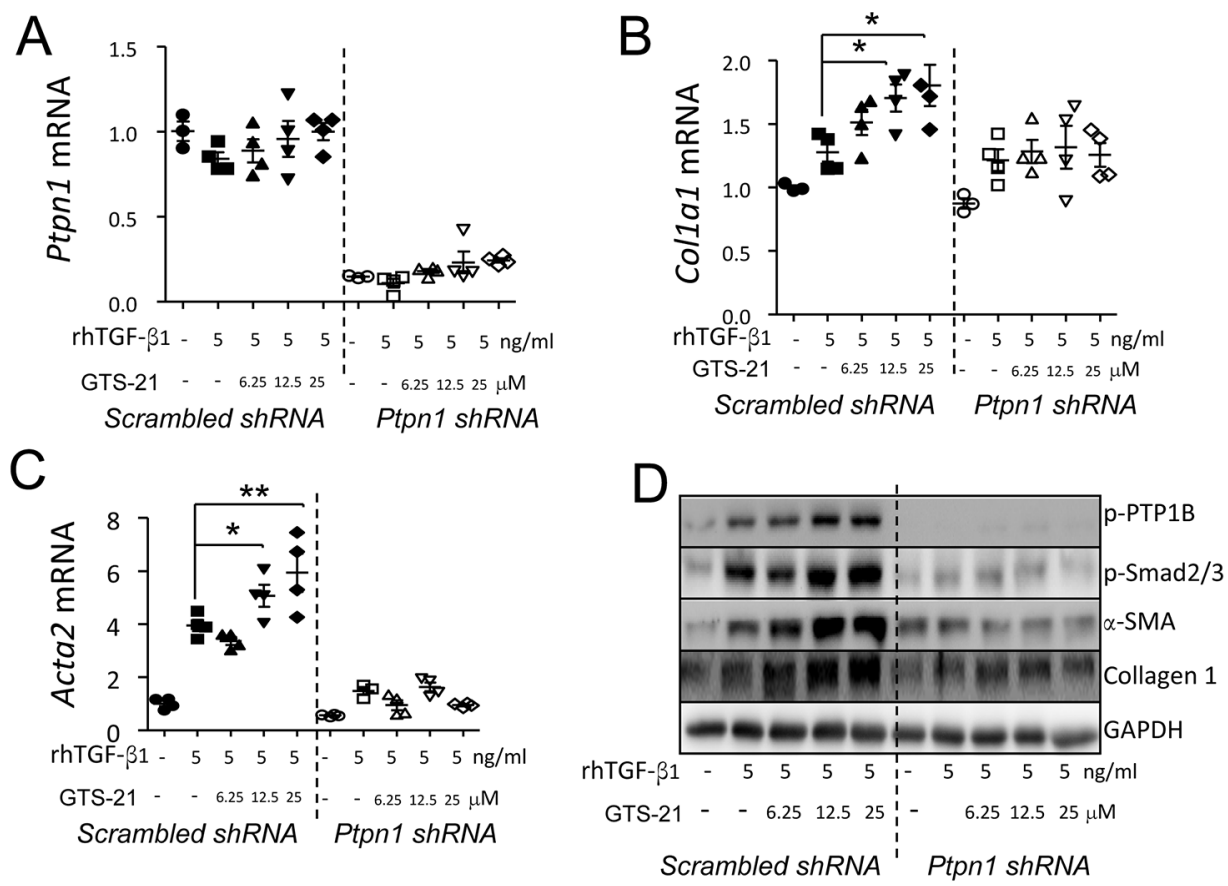

Figure 10. Activation of $\alpha 7 \mathrm{nAChR}$ enhances TGF- $\beta$ signaling in a PTP1B-dependent manner. (A-C) Effect of knockdown of (A) Ptpn 1 on (B) Colla 1 and (C) Acta2 mRNA in GTS-21 pretreated rhTGF- $\beta 1$-stimulated fibroblasts. The fibroblasts were first infected with pLKO. 1 scrambled or shRNA-Ptpn 1 lentivirus and then pretreated with GTS-21 (6.25, 12.5 and $25 \mu$ M separately; PBS was applied in the control group) and stimulated with rhTGF- $\beta 1$ ( $5 \mathrm{ng} / \mathrm{mL}$ ). The cells were harvested $24 \mathrm{~h}$ after rhTGF- $\beta$ stimulation. (D) Effect of knockdown of Ptpn 1 on expression of $\mathrm{p}$-Smad2/3, $\alpha$-SMA and collagen 1 in GTS-2 1 pretreated rhTGF- $\beta 1$-stimulated fibroblasts. Using the same experimental setting as Figure $8 \mathrm{~A}$, the fibroblasts were harvested $24 \mathrm{~h}$ after rhTGF- $\beta 1$ stimulation and lysed for immunoblotting. Experiments were repeated three times.

of $\alpha 7 \mathrm{nAChR}$ significantly reduced transcription of profibrotic genes (Acta2, Col1a1 and Fsp1) and $\alpha$-SMA expression at protein levels in BLM-challenged lung, which could reflect that $\alpha 7 \mathrm{nAChR}$ influenced the TGF- $\beta 1$ signaling pathway in BLM-induced lung fibrosis.

Both lung epithelial cells and fibroblasts are important for development of pulmonary fibrosis (67). TGF- $\beta$ signaling and transcription of fibrotic genes is essential for fibrogenesis $(68,69)$. Both lung epithelial cells (21) and fibroblasts (Figure 8A) express $\alpha 7 \mathrm{nAChR}$. In lung epithelial cells, BLM and TGF- $\beta 1$ induced Acta2 expression (Figures 8C, D), but $\alpha 7 \mathrm{nAChR}$ activation did not affect this change (Figures 8C, D). In lung fibroblasts, BLM failed to trigger Acta2 expression (Figure 8B); however, TGF- $\beta 1$ induced high levels of Acta2 expression, and $\alpha 7 \mathrm{nAChR}$ activation further boosted it (Figures 8E, F). Therefore, in vivo, activation of $\alpha 7 \mathrm{nAChR}$ might preferentially affect TGF- $\beta 1$ signaling or fibrogenesis in lung fibroblasts rather than epithelial cells. In fact, lung TGF$\beta 1$ levels were significantly increased in both BLM-challenged wild-type and $\alpha 7$ nAChR-deficient mice compared to saline-treated mice (Figure 6G). The findings further support that $\alpha 7 \mathrm{nAChR}$ activation enhances TGF- $\beta 1$ signaling rather than the amount of TGF- $\beta 1$. Macrophages and monocytes are major producers of proinflammatory cytokines, but inflammatory responses were not affected by $\alpha 7 \mathrm{nAChR}$ deficiency in this study.

In this study, we found that activation of $\alpha 7 \mathrm{nAChR}$ led to phosphorylation of PTP1B (Figures 8F, 9E and 10D). So far, the underlying mechanism of this event has not been clarified; however, silencing Ptpn1 abolished the upregulatory effects of activation of $\alpha 7 \mathrm{nAChR}$ on
TGF- $\beta$ signaling (Figure 10D) and transcription of profibrotic genes (Col1a1 and Acta2) (Figures 10B, C) in fibroblasts. This finding indicates that PTP1B is a key factor connecting activation of $\alpha 7$ $n A C h R$ to TGF- $\beta$ signaling. It has been reported that PTP1B participates in the development of fibrosis in liver (70) by activating hepatic stellate cells. PTP1B deficiency confers resistance to TGF- $\beta$ through Smad inhibition in hepatocytes (57). Therefore, it would be worthwhile to further investigate the relationship among activation of $\alpha 7 \mathrm{nAChR}, \mathrm{PTP} 1 \mathrm{~B}$ and TGF- $\beta$ signaling in lung fibroblasts so that we can find novel therapeutic targets for combating lung fibrosis.

Besides PTP1B, PTP- $\alpha$ (coded by Ptpra) has been reported to play a role in mediating promotion of profibrotic signaling pathways in fibroblasts through control of cellular responsiveness to TGF- $\beta$ (17). Similar to Chrna7 null mice, Ptpra ${ }^{-/-}$ 


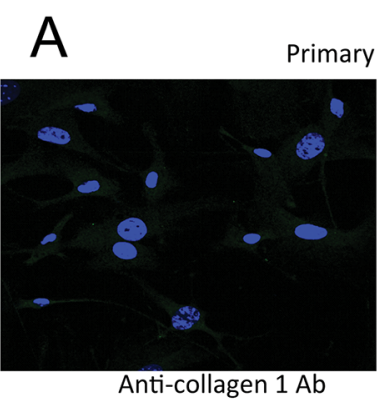

$(-)$
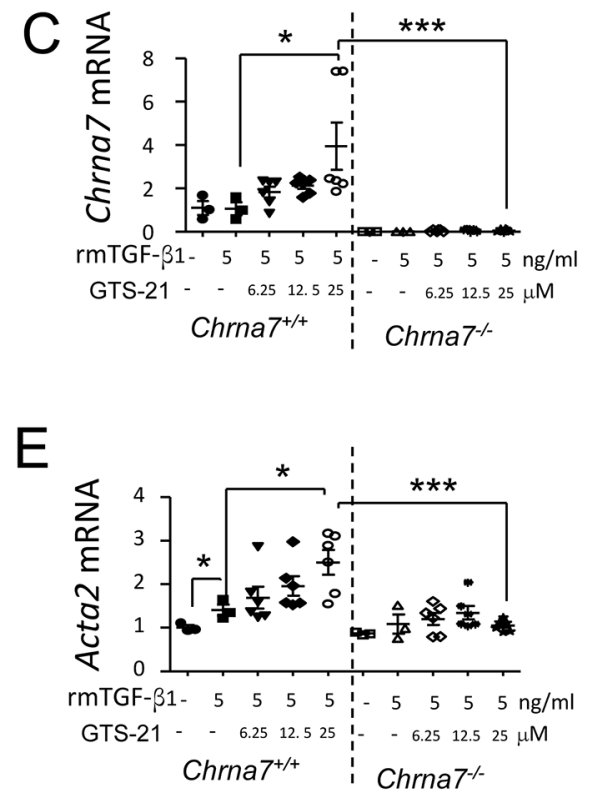

B

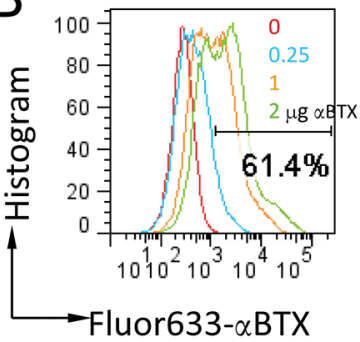

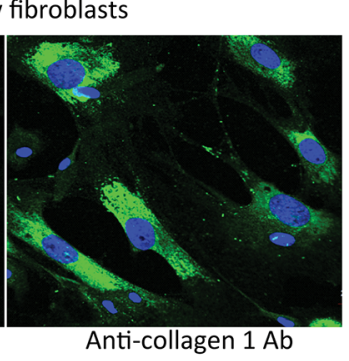

$(+)$

D

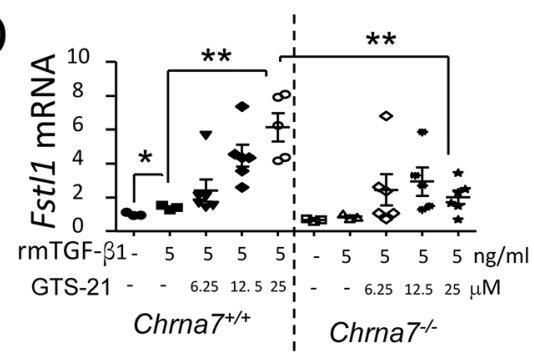

Figure 11. Effects of $\alpha 7 \mathrm{nAChR}$ activation on TGF- $\beta$ 1-induced lung profibrotic genes in mouse lung primary fibroblasts. (A) Immunofluorescence of mouse lung primary fibroblasts. The cultured mouse lung primary fibroblasts were labeled with or without rabbit anti-collagen 1 antibody. The stained cells were subjected to confocal microscopy. Green: FITC, collagen 1 positive; blue: DAPI, nucleus. (B) Flow cytometry analysis of $\alpha 7$ $\mathrm{nAChR}$ expression in mouse lung primary fibroblasts. The cells were collected and stained with fluor-633 $\alpha$-BTX at $0,0.5,1$ and $2 \mu \mathrm{g} / \mathrm{mL}$. (C-F) Activation of $\alpha 7 \mathrm{nAChR}$ affects profibrotic genes in rmTGF- $\beta 1$-stimulated fibroblasts $24 \mathrm{~h}$ after rmTGF- $\beta 1$ challenge. The cells were pretreated with GTS-21 (6.25, 12.5 and $25 \mu \mathrm{M}$ separately; PBS was applied in control group) 30 min before stimulation with rmTGF- $\beta 1(5 \mathrm{ng} / \mathrm{mL})$. The cells were harvested $24 \mathrm{~h}$ after rhTGF- $\beta$ stimulation. (C) Chrna7 mRNA. (D) Fstll mRNA. (E) Acta2 mRNA. (F) Colla 1 mRNA. " $p<0.05, " * p<0.01, " * p<0.001$ in compared groups. $N=3-6$ in each group. Data are mean $\pm \mathrm{SD}$. Data were pooled from two independent experiments.

mice were protected from pulmonary fibrosis induced by intratracheal BLM, with minimal alterations in the early inflammatory response or production of TGF- $\beta$ (17). Whether PTP family members share similar features in regulating the development of fibrosis is worth investigating.

\section{CONCLUSION}

Taken together, in the in vitro study, activation of $\alpha 7 \mathrm{nAChR}$ increased TGF$\beta$-induced phosphorylation of Smad2/3 and transcription of fibrogenic genes in fibroblasts. PTP1B is implicated in $\alpha 7$ $n A C h R$-activation enhanced TGF- $\beta$ signaling and profibrotic gene transcription in fibroblasts. In the in vivo study, deficiency of $\alpha 7 \mathrm{nAChR}$ lessened BLMinduced lung fibrosis by suppressing transcription of profibrotic genes, but did not affect transcription of proinflammatory genes. Therefore, $\alpha 7 \mathrm{nAChR}$ is a key regulator of lung fibrogenesis via upregulation of TGF- $\beta$ signaling and transcription of profibrotic factors in the fibroblasts.

\section{ACKNOWLEDGMENTS}

The authors appreciate Yiyi Jiang for breeding and genotyping animals and Bangguo Qian for technical assistance in histological staining.

Our research is supported by the Major Research plan of NSFC 91542105, NSFC 81270139 and 81470269; the 100 Talents Project of the CAS 2A2013311211004; the Knowledge Innovation Program of CAS 24P201200201; the STS Plan of CAS KFJ-EW-STS-098); and Shanghai Key Grant 12JC1408900.

\section{DISCLOSURE}

The authors declare that they have no competing interests as defined by Molecular Medicine or other interests that might be perceived to influence the results and discussion reported in this paper.

\section{REFERENCES}

1. O'Dwyer DN, Armstrong ME, Kooblall M, Donnelly SC. (2015) Targeting defective Toll-like receptor-3 function and idiopathic pulmonary fibrosis. Expert Opin. Ther. Targets. 19:507-14.

2. Spagnolo P, Maher TM, Richeldi L. (2015) Idiopathic pulmonary fibrosis: Recent advances on pharmacological therapy. Pharmacol. Ther. 152:18-27.

3. Borensztajn K, Crestani B, Kolb M. (2013) Idiopathic pulmonary fibrosis: from epithelial injury to biomarkers-insights from the bench side. Respiration. 86:441-52.

4. Spagnolo P, Rossi G, Cavazza A. (2014) Pathogenesis of idiopathic pulmonary fibrosis and its clinical implications. Exp. Rev. Clin. Immunol. 10:1005-17.

5. Margadant C, Sonnenberg A. (2010) Integrin-TGF-beta crosstalk in fibrosis, cancer and wound healing. EMBO Rep. 11:97-105.

6. Lawson WE, et al. (2005) Characterization of fibroblast-specific protein 1 in pulmonary fibrosis. Am. J. Respir. Crit. Care Med. 171:899-907.

7. Dong $\mathrm{Y}$, et al. (2015) Blocking follistatin-like 1 attenuates bleomycin-induced pulmonary fibrosis in mice. J. Exp. Med. 212:235-52. 
8. Santibanez JF, Quintanilla M, Bernabeu C. (2011) TGF-beta/TGF-beta receptor system and its role in physiological and pathological conditions. Clin. Sci. 121:233-51.

9. Aumiller V, Balsara N, Wilhelm J, Gunther A, Konigshoff M. (2013) WNT/beta-catenin signaling induces IL-1beta expression by alveolar epithelial cells in pulmonary fibrosis. Am. J. Respir. Cell Mol. Biol. 49:96-104.

10. Madala SK, et al. (2014) Dual targeting of MEK and PI3K pathways attenuates established and progressive pulmonary fibrosis. PloS One. 9:e86536.

11. Ju W, et al. (2012) Inhibition of alpha-SMA by the ectodomain of FGFR2c attenuates lung fibrosis. Mol. Med. 18:992-1002.

12. Roach KM, Wulff H, Feghali-Bostwick C, Amrani Y, Bradding P. (2014) Increased constitutive alphaSMA and Smad2/3 expression in idiopathic pulmonary fibrosis myofibroblasts is KCa3.1-dependent. Respir. Res. 15:155.

13. Chacko BM, et al. (2004) Structural basis of heteromeric smad protein assembly in TGF-beta signaling. Mol. Cell. 15:813-23.

14. Xu P, Liu J, Derynck R. (2012) Post-translational regulation of TGF-beta receptor and Smad signaling. FEBS letters 586:1871-84

15. Hubner RH, et al. (2008) Standardized quantification of pulmonary fibrosis in histological samples. BioTechniques. 44:507-17

16. Song N, et al. (2015) Vagotomy attenuates bleomycin-induced pulmonary fibrosis in mice. Sci. Rep. 5:13419.

17. Aschner $Y$, et al. (2014) Protein tyrosine phosphatase alpha mediates profibrotic signaling in lung fibroblasts through TGF-beta responsiveness. Am. J. Pathol. 184:1489-1502.

18. Pavlov VA, Tracey KJ. (2015) Neural circuitry and immunity. Immunol. Res. 63:38-57.

19. Fox B, Bull TB, Guz A. (1980) Innervation of alveolar walls in the human lung: an electron microscopic study. J. Anat. 131:683-92.

20. Hertweck MS, Hung KS. (1980) Ultrastructural evidence for the innervation of human pulmonary alveoli. Experientia. 36:112-13.

21. Su X, et al. (2007) Activation of the alpha7 $\mathrm{nAChR}$ reduces acid-induced acute lung injury in mice and rats. Am. J. Respir. Cell Mol. Biol. 37:186-92.

22. Su X, Matthay MA, Malik AB. (2010) Requisite role of the cholinergic alpha7 nicotinic acetylcholine receptor pathway in suppressing Gramnegative sepsis-induced acute lung inflammatory injury. J. Immunol. 184:401-10.

23. Wu H, Li L, Su X. (2014) Vagus nerve through alpha7 nAChR modulates lung infection and inflammation: models, cells, and signals. BioMed Res. Int. 2014:283525.

24. Pieper MP, Chaudhary NI, Park JE. (2007) Acetylcholine-induced proliferation of fibroblasts and myofibroblasts in vitro is inhibited by tiotropium bromide. Life Sci. 80:2270-73.
25. Oben JA, Yang S, Lin H, Ono M, Diehl AM. (2003) Acetylcholine promotes the proliferation and collagen gene expression of myofibroblastic hepatic stellate cells. Biochem. Biophys. Res. Commun. 300:172-77.

26. Arredondo J, et al. (2003) Central role of fibroblast alpha3 nicotinic acetylcholine receptor in mediating cutaneous effects of nicotine. $L a b$. Invest. 83:207-25.

27. Sekhon HS, Keller JA, Proskocil BJ, Martin EL, Spindel ER. (2002) Maternal nicotine exposure upregulates collagen gene expression in fetal monkey lung. Association with alpha7 nicotinic acetylcholine receptors. Am. J. Respir. Cell Mol. Biol. 26:31-41.

28. Su X, Matthay MA. (2009) Role of protease activated receptor 2 in experimental acute lung injury and lung fibrosis. Anatom. Rec. 292:580-6.

29. Su X, Looney M, Robriquet L, Fang X, Matthay MA. (2004) Direct visual instillation as a method for efficient delivery of fluid into the distal airspaces of anesthetized mice. Exp. Lung Res. 30:479-93.

30. Su X, et al. (2011) Role of CFTR expressed by neutrophils in modulating acute lung inflammation and injury in mice. Inflamm. Res. 60:619-32.

31. O'Dwyer DN, et al. (2013) The Toll-like receptor $3 \mathrm{~L} 412 \mathrm{~F}$ polymorphism and disease progression in idiopathic pulmonary fibrosis. Am. J. Respir. Crit. Care Med. 188:1442-50.

32. Ashcroft T, Simpson JM, Timbrell V. (1988) Simple method of estimating severity of pulmonary fibrosis on a numerical scale. J. Clin. Pathol. 41:467-70.

33. Formigli L, et al. (2007) Paracrine effects of transplanted myoblasts and relaxin on post-infarction heart remodelling. J. Cell. Mol. Med. 11:1087-100.

34. Peng J, et al. (2015) Uterine activin receptor-like kinase 5 is crucial for blastocyst implantation and placental development. Proc. Natl. Acad. Sci. USA. 112: E5098-107.

35. Matsubara T, et al. (2008) BMP2 regulates Osterix through Msx2 and Runx2 during osteoblast differentiation. J. Bio. Chem. 283:29119-125.

36. Kwapiszewska G, et al. (2005) Expression profiling of laser-microdissected intrapulmonary arteries in hypoxia-induced pulmonary hypertension. Respir. Res. 6:109.

37. Scheiermann C, et al. (2012) Adrenergic nerves govern circadian leukocyte recruitment to tissues. Immunity. 37:290-301.

38. Zhou B, et al. (2011) Adult mouse epicardium modulates myocardial injury by secreting paracrine factors. J. Clin. Invest. 121:1894-904.

39. Nguyen KD, et al. (2011) Alternatively activated macrophages produce catecholamines to sustain adaptive thermogenesis. Nature. 480:104-8.

40. Yeo SJ, Yoon JG, Hong SC, Yi AK. (2003) CpG DNA induces self and cross-hyporesponsiveness of RAW264.7 cells in response to CpG DNA and lipopolysaccharide: alterations in IL-1 receptor-associated kinase expression. J. Immunol. 170:1052-61.
41. Zhang $Y$, et al. (2015) Apigenin induces derma collagen synthesis via smad2/3 signaling pathway. Eur. J. Histochem. 59:2467.

42. Li J, et al. (2011) S100A expression in normal corneal-limbal epithelial cells and ocular surface squamous cell carcinoma tissue. Mol. Vis. 17:2263-71.

43. Livak KJ, Schmittgen TD. (2001) Analysis of relative gene expression data using real-time quantitative PCR and the 2(-Delta Delta C(T)) method. Methods. 25:402-8.

44. Smith RE, et al. (1995) A role for C-C chemokines in fibrotic lung disease. J. Leukoc. Biol. 57:782-7.

45. Looney MR, Su X, Van Ziffle JA, Lowell CA, Matthay MA. (2006) Neutrophils and their Fc gamma receptors are essential in a mouse model of transfusion-related acute lung injury. J. Clin. Invest. 116:1615-23.

46. Reardon C, et al. (2013) Lymphocyte-derived ACh regulates local innate but not adaptive immunity. Proc. Natl. Acad. Sci. USA. 110:1410-15.

47. Frankel SK, et al. (2006) TNF-alpha sensitizes normal and fibrotic human lung fibroblasts to Fas-induced apoptosis. Am. J. Respir. Cell Mol. Biol. 34:293-304

48. Yang Y, et al. (2002) Detection of antivimentin antibody in sera of patients with idiopathic pulmonary fibrosis and non-specific interstitial pneumonia. Clin. Exper. Immunol. 128:169-74.

49. Wynes MW, et al. (2011) Increased cell surface Fas expression is necessary and sufficient to sensitize lung fibroblasts to Fas ligation-induced apoptosis: implications for fibroblast accumulation in idiopathic pulmonary fibrosis. J. Immunol. 187:527-37.

50. Huang M, et al. (2015) Inhibition of connective tissue growth factor attenuates paraquatinduced lung fibrosis in a human MRC-5 cell line. Environ. Toxicol. 31:1620-26

51. O'Beirne SL, et al. (2015) CXCL9 Regulates TGF-beta1-Induced Epithelial to Mesenchymal Transition in Human Alveolar Epithelial Cells. J. Immunol. 195:2788-96.

52. Kim KK, et al. (2006) Alveolar epithelial cell mesenchymal transition develops in vivo during pulmonary fibrosis and is regulated by the extracellular matrix. Proc. Natl. Acad. Sci. USA. 103:13180-5.

53. Camara J, Jarai G. (2010) Epithelial-mesenchymal transition in primary human bronchial epithelial cells is Smad-dependent and enhanced by fibronectin and TNF-alpha. Fibrogenesis Tissue Repair. 3:2.

54. Kasai H, Allen JT, Mason RM, Kamimura T, Zhang Z. (2005) TGF-beta1 induces human alveolar epithelial to mesenchymal cell transition (EMT). Respir. Res. 6:56.

55. Ono M, et al. (2015) Mesenchymal stem cells correct inappropriate epithelial-mesenchyme relation in pulmonary fibrosis using stanniocalcin-1. Mol. Ther. 23:549-60. 
56. Su X, Wang L, Song Y, Bai C. (2004) Inhibition of inflammatory responses by ambroxol, a mucolytic agent, in a murine model of acute lung injury induced by lipopolysaccharide. Intensive Care Med. 30:133-40.

57. Ortiz C, et al. (2012) Protein-tyrosine phosphatase 1B (PTP1B) deficiency confers resistance to transforming growth factor-beta (TGF-beta)-induced suppressor effects in hepatocytes. J. Biol. Chem. 287:15263-74.

58. Chua F, Gauldie J, Laurent GJ. (2005) Pulmonary fibrosis: searching for model answers. Am. J. Respir. Cell Mol. Biol. 33:9-13.

59. Arizmendi N, et al. (2014) Rac2 is involved in bleomycin-induced lung inflammation leading to pulmonary fibrosis. Respir. Res. 15:71.

60. Cai Y, et al. (2015) Transgenically-expressed secretoglobin 3A2 accelerates resolution of bleomycin-induced pulmonary fibrosis in mice. $B M C$ Pulm. Med. 15:72.

61. Tao B, et al. (2014) Myeloid-specific disruption of tyrosine phosphatase Shp2 promotes alternative activation of macrophages and predisposes mice to pulmonary fibrosis. J. Immunol. 193:2801-11.

62. Gibbons MA, et al. (2011) Ly6Chi monocytes direct alternatively activated profibrotic macrophage regulation of lung fibrosis. Am. J. Respir. Crit. Care Med. 184:569-81.

63. Murthy S, et al. (2015) Alternative activation of macrophages and pulmonary fibrosis are modulated by scavenger receptor, macrophage receptor with collagenous structure. FASEB J. 29:3527-36.

64. Mora AL, et al. (2006) Activation of alveolar macrophages via the alternative pathway in herpesvirus-induced lung fibrosis. Am. J. Respir. Cell Mol. Biol. 35:466-73.

65. Ckless K, et al. (2008) Inhibition of arginase activity enhances inflammation in mice with allergic airway disease, in association with increases in protein S-nitrosylation and tyrosine nitration. J. Immunol. 181:4255-64

66. North ML, Khanna N, Marsden PA, Grasemann H, Scott JA. (2009) Functionally important role for arginase 1 in the airway hyperresponsiveness of asthma. Am. J. Physiol. Lung Cell. Mol. Physiol. 296: L911-20.

67. Sakai N, Tager AM. (2013) Fibrosis of two: Epithelial cell-fibroblast interactions in pulmonary fibrosis. Biochim. Biophys. Acta. 1832:911-21.

68. Gauldie J, et al. (2006) Smad3 signaling involved in pulmonary fibrosis and emphysema. Proc. Am. Thorac. Soc. 3:696-702.

69. Cutroneo KR, White SL, Phan SH, Ehrlich HP. (2007) Therapies for bleomycin induced lung fibrosis through regulation of TGF-beta1 induced collagen gene expression. J. Cell. Physiol. 211:585-9.

70. Chen PJ, et al. (2016) PTP1B confers liver fibrosis by regulating the activation of hepatic stellate cells. Toxicol. Appl. Pharmacol. 292:8-18.
Cite this article as: Sun P, et al. (2017) Deficiency of $\alpha 7$ nicotinic acetylcholine receptor attenuates bleomycin-induced lung fibrosis in mice. Mol. Med. 23:34-49. 